Review

\title{
Overview of Salvia miltiorrhiza as a Potential Therapeutic Agent for Various Diseases: An Update on Efficacy and Mechanisms of Action
}

\author{
Inyong Jung ${ }^{1}$, Hyerin Kim ${ }^{1}$, Seongcheol Moon ${ }^{1}$, Hyuk Lee ${ }^{1}$ and Bonglee Kim ${ }^{1,2, *(D)}$ \\ 1 College of Korean Medicine, Kyung Hee University, Hoegidong Dongdaemungu, Seoul 05253, Korea; \\ jaugus@khu.ac.kr (I.J.); hellohihr@khu.ac.kr (H.K.); kanyewest@khu.ac.kr (S.M.); well0304@khu.ac.kr (H.L.) \\ 2 Korean Medicine-Based Drug Repositioning Cancer Research Center, College of Korean Medicine, \\ Kyung Hee University, Hoegidong Dongdaemungu, Seoul 05253, Korea \\ * Correspondence: bongleekim@khu.ac.kr; Tel.: +82-2-961-9217
}

Received: 16 August 2020; Accepted: 11 September 2020; Published: 13 September 2020

\begin{abstract}
Salvia miltiorrhiza Bunge (S. miltiorrhiza) is a medicinal herb that has been used for the treatment for various diseases such as cardiovascular and cerebrovascular diseases in East Asia including Korea. Considering its extensive usage as a therapeutic agent for multiple diseases, there is a need to review previous research regarding its therapeutic benefits and their mechanisms. Therefore, we searched PubMed and PubMed Central for articles reporting its therapeutic effects on certain disease groups including cancers, cardiovascular, liver, and nervous system diseases. This review provides an overview of therapeutic benefits and targets of S. miltiorrhiza, including inflammation, fibrosis, oxidative stress, and apoptosis. The findings on multi-functional properties of S. miltiorrhiza discussed in this article support the efficacy of $S$. miltiorrhiza extract on various diseases, but also call for further research on the multiple mechanisms that mediate its therapeutic effects.
\end{abstract}

Keywords: Salvia miltiorrhiza Bunge; dansam; cancer; cardiovascular diseases; liver diseases; nervous system diseases; anti-inflammation; antioxidant

\section{Salvia miltiorrhiza Bunge}

Salvia miltiorrhiza Bunge (S. miltiorrhiza), also known as dansam in Korean and danshen in Chinese, has been used for the treatment of cardiovascular and cerebrovascular diseases, especially in Asia [1]. It is a deciduous perennial plant which belongs to genus Salvia of Lamiaceae family [2]. The active components of S. miltiorrhiza are divided into two groups, one of which is water-soluble phenolics including salvianolic acid A (Sal A), salvianolic acid B (Sal B), lithospermic acid, rosmarinic acid, and R-(+)- $\beta$-(3,4-dihydroxyphenyl)lactic acid, named danshensu [3] and the other is lipophilic tanshinones including tanshinone I, tanshinone IIA, tanshinone IIB, cryptotanshinone, and dihydrotanshinone I [4]. Salvianolic acids (including Sal A and Sal B), the most abundant compounds from S. miltiorrhiza, are known to exhibit diverse biological activities such as antioxidant [5], anti-inflammatory [6], antithrombotic [7], and cardioprotective activities [8,9], while tanshinones show antitumor [10], cardioprotective [11], neuroprotective and analgesic activities [12], and so forth.

Dried roots of S. miltiorrhiza, extracted with various solvents, have been reported to have therapeutic effects on a variety of diseases including cancers [13], cardiovascular diseases [14], liver diseases [15], and nervous system diseases [16]. So far, there have been a small number of review articles on S. miltiorrhiza extract, most of which focused on its therapeutic use on a certain disease, mainly cardiovascular diseases $[17,18]$ or Alzheimer's disease [19]. Given its wide usage on many different diseases, there is a need to review studies addressing therapeutic effects and mechanisms 
of action of S. miltiorrhiza in different groups of diseases. Thus, we aim to review the experimental research according to groups of diseases, which will ultimately contribute to a better understanding of its potentials.

\section{Methods}

\subsection{Search Strategy}

Research papers regarding S. miltiorrhiza and related diseases were collected from June 2019 to April 2020 using the PubMed and PubMed Central databases (www.ncbi.gov/pubmed). Medical Subject Headings (MeSH) terms such as "Neoplasms", "Cardiovascular diseases", "Liver Diseases", or "Nervous system diseases" and keywords such as "Salvia miltiorrhiza", "dansam", "danshen", "cancer", "heart", "liver", "brain", "nerve", "memory", “Alzheimer's", "dementia", and "extract" were combined to search for relevant articles. To identify articles of interest, all articles retrieved from two databases were manually reviewed and checked for duplication.

\subsection{Study Selection Criteria}

The inclusion criteria were as follows: (1) articles that reported on the efficacy of whole herb extracts of S. miltiorrhiza in any dosage form (extract, injection, tablet, pill, etc.), (2) studies where in vitro, in vivo, or ex vivo experiment were performed, (3) original research articles, (4) articles written in English, (5) articles published between January 2014 and December 2019. The exclusion criteria were: (1) review articles, (2) articles on diseases other than cancer, cardiovascular diseases, liver diseases, and nervous system diseases.

\subsection{Data Extraction}

The extracted information included the publication year, the first author's name, the disease targeted, extractant, cell line/animal model type, dose and duration of extract administered, efficacy, and mechanisms of action (if reported).

\section{Cancer}

Cancer is a major cause of death worldwide. The incidence and mortality of cancers have risen over the past decade $[20,21]$. They differ between men and women; for example, the age-standardized incidence rates for all cancers combined in 2018 were around 20 percent higher in men than in women (a difference of 36 per 100,000), and mortality rates 50 percent higher in men than in women (a difference of 39.6 per 100,000) [21]. They vary across regions as well; to illustrate, the incidence for adult liver cancers and hepatocellular carcinoma is increasing in the Western countries, while the trends are quite the opposite in Asia with the numbers remaining still high [22]. This global health issue has been addressed with great interest within the scientific and medical community and, as a result, cancer therapeutics such as chemotherapy, immunotherapy, and targeted therapy have continued to improve over the past six decades [23]. However, several studies reported chemotherapy-induced adverse effects, such as neurotoxicity in patients treated with oxaliplatin [24], thalidomide [25], or cytarabine [26]; nausea and vomiting with cisplatin [27] and the AC (doxorubicin/cyclophosphamide) combination [28]; and bone loss with methotrexate [29]. At this point, there is an inevitable need for a therapeutic agent with no or less side-effects, which will help to cope with the global burden of cancer. Results from multiple studies suggest $S$. miltiorrhiza extract should be considered a plausible option.

\section{Cancer and S. miltiorrhiza}

Several studies about the anti-cancer effect of S. miltiorrhiza have been reported (Table 1). According to Kim et al., treatment with $70 \%$ ethanol extract of S. miltiorrhiza inhibited matrix metalloproteinase (MMP)-9 expression and cell invasion in 12-O-tetradecanoylphorbol-13-acetate (TPA)-induced MCF-7 breast cancer cells, possibly through down-regulating the mitogen-activated 
protein kinase (MAPK)/activator protein-1 (AP-1) signaling pathway [30]. Treatment with S. miltiorrhiza extract at a dose of $50 \mu \mathrm{g} / \mathrm{mL}$ for $24 \mathrm{~h}$ decreased the phosphorylation of MAPKs, including extracellular signal-regulated kinase (ERK), c-Jun N-terminal kinase (JNK), and p38. In addition, it down-regulated phospho (p)-c-Jun expression, implying that S. miltiorrhiza extract had an inhibitory effect on TPA-induced MMP-9 expression through blocking the activation of the transcription factor AP-1, a dimer consisting of either Jun/Jun homodimers or Fos/Jun heterodimeric complexes. Wu et al. found that an herbal mixture extract named CASE (Astragalus and Salvia miltiorrhiza water/ethanol extract [71:1.85]) suppressed hepatocellular carcinoma (HCC) progression in vivo (Diethylnitrosamine [DEN]-induced HCC in rats) and in vitro (TGF- $\beta_{1}$-stimulated HepG2 cells) [31]. At first, 60, 120, or $240 \mathrm{mg} / \mathrm{kg}$ of CASE was orally administered to Sprague Dawley (SD) rat with DEN-induced HCC for 28 days, which increased relative microRNA (miR)-145 expression but decreased relative miR-21 expression. In vivo, BALB/c mice xenografted with HepG2 cells were intragastrically injected with $310 \mathrm{mg} / \mathrm{kg}$ of CASE once every four days for 28 days, which reversely regulated miR-145 antagomir/miR-21 agomir-mediated Smad3 phosphorylation. CASE up-regulated miR-145 and p-Smad3C expression and down-regulated miR-21, p-Smad3L, p-ERK1/2, p-JNK1/2, and p-p38 expression. According to Boye et al., the same herbal mixture extract (CASE) also affected MAPK-regulated TGF- $\beta /$ Smad signaling in HCC [32]. In an in vivo mouse model of DEN-induced HCC, administration of CASE at doses of 60, 120, or $240 \mathrm{mg} / \mathrm{kg}$ for 12 or 16 weeks suppressed p-ERK, p-JNK, and p-p38 expression. On the other hand, in vivo pretreatment of hepatic stellate cells (HSCs) and/or HepG2 cells with CASE at doses of 20,40 , or $80 \mu \mathrm{g} / \mathrm{mL}$ for $24 \mathrm{~h}$ before their stimulation with TGF- $\beta 1$ decreased p-ERK and p-JNK expression, while it increased p-p38 expression. Pretreatment with CASE also concentration-dependently decreased TGF- $\beta 1$-induced phosphorylation of oncogenic pSmad3L in HSC and HepG2 cells; reduced nuclear import of Smad4; enhanced the phosphorylation of tumor suppressor pSmad3C especially in HepG2 cells; reduced the expression and nuclear relocation of importins (Imp) 7/8; and suppressed plasminogen activator inhibitor (PAI)-1 gene expression. In Kim et al.'s study, after treatment of U266 (human multiple myeloma) and U937 (human myeloid leukemia) cells with $99.9 \%$ ethyl alcohol extract of S. miltiorrhiza at doses of $25,50,100$, or $200 \mu \mathrm{g} / \mathrm{mL}$ for $24 \mathrm{~h}$, cell viability was inhibited in a dose-dependent manner [33]. Further, treatment with S. miltiorrhiza extract at doses of 25 or $50 \mu \mathrm{g} / \mathrm{mL}$ for $24 \mathrm{~h}$ increased reactive oxygen species (ROS) generation; enhanced phosphorylation of activating transcription factor 4 (ATF4), eukaryotic initiation factor 2 (eIf2), and protein kinase RNA-like endoplasmic reticulum kinase (PERK); and increased CCAAT-enhancer-binding protein homologous protein (CHOP) activation and cleavage of poly ADP-ribose polymerase (PARP) and caspase-3. In addition, $24 \mathrm{~h}$ treatment with $\mathrm{S}$. miltiorrhiza extract significantly elevated the expression of tumor suppressor miR-216b at a dose of $50 \mu \mathrm{g} / \mathrm{mL}$, whereas it down-regulated its target protein, c-Jun, at doses of 25 or $50 \mu \mathrm{g} / \mathrm{mL}$. According to Ye et al., methanol extract of S. miltiorrhiza could inhibit the growth of non-small cell lung cancer (NSCLC) via induction of apoptosis through mitochondrial apoptotic pathway and phosphatase and tensin homolog (PTEN)-mediated inhibition of the phosphoinositide 3 kinase (PI3K)/Akt pathway [34]. In vitro treatment with S. miltiorrhiza extract at doses of 20 or $40 \mu \mathrm{g} / \mathrm{mL}$ for $24 \mathrm{~h}$ induced apoptosis in Glc-82 cells as observed with Annexin V-FITC/PI staining and up-regulated the expression levels of cleaved caspase-3, -9 , and PARP1, suggesting the involvement of the mitochondrial apoptotic pathway. In addition, it increased the expression of $\mathrm{Bcl}-2$-associated $\mathrm{X}$ protein (Bax) and the tumor-suppressor proteins $\mathrm{p} 53$ and $\mathrm{p} 21$, while it decreased the expression of B-cell lymphoma 2 (Bcl-2) and B-cell lymphoma-extra large (Bcl-xl), both of which are anti-apoptotic components of Bcl-2 family. Further, treatment with $S$. miltiorrhiza extract also inhibited the phosphorylation of Akt and increased the activity of its upstream inhibitor, PTEN. In vivo, administration of $S$. miltiorrhiza extract at a dose of $40 \mathrm{mg}$ for 22 days suppressed the growth of lung cancer Glc-82 xenografts in Balb/c mice. Lee et al. demonstrated that the arsenic herbal mixture PROS (tetraarsenic hexoxide [PR] + Olendlandia diffusa and Salvia miltiorrhiza extract (5:2) [OS]) showed apoptotic and anti-angiogenic effects in non-small-cell lung cancer cells (NSCLCs) via inhibition of signal transducer and activator of transcription 3 (STAT3)/vascular endothelial growth 
factor (VEGF)/cyclin-dependent kinase 2 axis signaling [35]. Treatment with PROS ( $2.5 \mu \mathrm{g} / \mathrm{mL}$ PR + $180 \mu \mathrm{g} / \mathrm{mL}$ OS) for $24 \mathrm{~h}$ exerted significant cytotoxic effects on A549 or H460 better than PR or OS alone and induced apoptosis and S phase arrest, as assessed by DAPI staining and cell cycle analysis. Further, PROS treatment decreased the phosphorylation of STAT3, ERK, proto-oncogene Src, Akt, cyclooxygenase 2 (COX-2), and suppressor of cytokine signaling 1 (SOCS-1) and subsequently inhibited the binding of STAT3 with VEGF or CDK2. PROS also inhibited VEGF-induced proliferation, migration, and tube formation in human umbilical vein endothelial cells (HUVECs) and ex vivo angiogenesis in chick chorioallantoic membranes (CAMs). PROS treatment down-regulated the phosphorylation of VEGFR2, Src, and STAT3 in HUVECs. In the H460 xenograft model, subcutaneous injection of PROS down-regulated STAT3 and VEGF expression and caspase-3 activation. In Wang et al.'s study, either double-distilled water (ddH2O), 95\% ethanol, or 1:1 water/ethanol extract of S. miltiorrhiza was added to two human oral squamous cell carcinoma (OSCC) cell lines, HSC-3 and OC-2, and it turned out that $95 \%$ ethanol extract of $S$. miltiorrhiza showed the greatest antioxidant and radical scavenging capabilities [36]. After treatment of HSC-3 cells with S. miltiorrhiza alcohol extract at doses of 10, 25, or $50 \mu \mathrm{g} / \mathrm{mL}$ for 48 or $72 \mathrm{~h}$, significant decreases in the expression of X-linked inhibitor of apoptosis protein (XIAP) and survivin were observed but there were no changes in the levels of mitochondrial membrane potential $(\Delta \Psi \mathrm{m})$, antiapoptotic proteins (Bcl-2 and Bcl-xL), and proapoptotic proteins (Bax and Bcl-2 associated agonist of cell death [Bad]). In vivo, BALB/c NU mice xenografted with HSC-3 tumor were intraperitoneally injected with 50 or $100 \mathrm{mg} / \mathrm{kg}$ of $S$. miltiorrhiza extract for 34 days, which resulted in the suppression of tumor growth without any significant impacts on mouse body weights; as for biological markers, treatment with S. miltiorrhiza extract led to decreased expression of XIAP and survivin but not Bcl-2 family members. Yang et al. examined the antiproliferative effect of S. miltiorrhiza extract on oral cancer cells [37]. In vitro, 95\% ethanol extract of S. miltiorrhiza was added to three OSCC cell lines SAS, SCC25, and Oec-ml (at doses between 0-30 $\mu \mathrm{g} / \mathrm{mL}$ for $24 \mathrm{~h}$ ) and six KB drug-resistant OSCC cell lines (at doses between $0-80 \mu \mathrm{g} / \mathrm{mL}$ for $24 \mathrm{~h}$ ). In vivo, oral cancer SAS xenograft mice were administered with $S$. miltiorrhiza extract at a dose of $10 \mathrm{mg} / \mathrm{kg}$ for 32 days. Treatment with S. miltiorrhiza extract, both in vitro and in vivo, induced apoptosis, as evidenced by the increased active caspase-3 expression and decreased XIAP expression. According to Lee et al., acetonitrile extract of $S$. miltiorrhiza prevented the progression of prostate cancer cells through the generation of intracellular ROS generation [38]. Treatment with S. miltiorrhiza extract at doses of 5, 20 , or $100 \mu \mathrm{g} / \mathrm{mL}$ for 24 or $48 \mathrm{~h}$ dose-dependently inhibited the growth of three prostate cancer cell lines (PC-3, LNCap, and DU-145) as measured by trypan blue assay. In addition, treatment with S. miltiorrhiza extract at a dose of $20 \mu \mathrm{g} / \mathrm{mL}$ for 24,48 , or $72 \mathrm{~h}$ induced cell cycle arrest at G1/S phase in PC-3 cells; it increased the protein expression of the cyclin-dependent kinase inhibitor p21 and decreased the protein expression of cyclin-dependent kinase 2 (CDK2), CDK4, and cyclin D1 protein. It also induced apoptosis in PC-3 cells as determined by TUNEL assay; it decreased the expression of anti-apoptotic Bcl-2 protein and increased the protein expression of apoptotic inducers such as caspase-9, caspase-3, and PARP. In vitro, PC-3 xenograft mouse model was injected with S. miltiorrhiza extract at doses of $100 \mathrm{mg} / \mathrm{kg}$ for 6 weeks. Both in vitro and in vivo, intracellular ROS generation was increased, which was considered to mediate the cytotoxic effect on prostate cancer cells. Sung et al. reported that $100 \%$ ethanol or $100 \%$ acetone extract of S. miltiorrhiza showed cytotoxicity against human cancer cell lines [39]. After treatment of AGS, A549, HCT116, LNCaP, and MCF-7 cells with S. miltiorrhiza extract (at doses of 5, 10, 20, $40 \mu \mathrm{g} / \mathrm{mL}$ for $24 \mathrm{~h}$ ), p-JNK, p-ERK1/2, p-p38, cleaved-caspase-3, $-7,-9$, and cleaved poly ADP-ribose polymerase (c-PARP) expression were elevated. In contrast, it decreased the expression of nuclear p65, thereby inhibiting the progression of cancer cells. Wu et al. demonstrated that dichloromethane-methanol (1:1) extract of $S$. miltiorrhiza induced intrinsic apoptosis in various drug-sensitive and multidrug-resistant cancer cells [40]. Treatment with S. miltiorrhiza extract at doses of 3,10, or $30 \mu \mathrm{g} / \mathrm{mL}$ for $1 \mathrm{~h}$ induced ROS production in CCRF-CEM cells. They also reported that S. miltiorrhiza extract induced apoptosis through caspases and a PARP-dependent pathway, as evidenced by the increased levels of cleaved caspase-3, -7, -9 and PARP upon treatment 
with S. miltiorrhiza extract at doses between 5-40 $\mu \mathrm{g} / \mathrm{mL}$. After treatment of CCRF-CEM cells with S. miltiorrhiza extract at a dose of $20 \mu \mathrm{g} / \mathrm{mL}$ for $24 \mathrm{~h}$, TNF- $\alpha$-induced translocation of p65 from cytoplasm to the nucleus was inhibited; when treated for $2 \mathrm{~h}$, p-JNK, p-ERK1/2, and p-p38 expression were up-regulated. Therapeutic targets of S. miltiorrhiza in cancers are elucidated in Figure 1. 
Table 1. Cancer and S. miltiorrhiza.

\begin{tabular}{|c|c|c|c|c|c|c|}
\hline Disease & Extract & Experimental Model & Dose; Duration & Efficacy & Mechanism & Reference \\
\hline Breast cancer & $70 \%$ ethanol & MCF-7 & $50 \mu \mathrm{g} / \mathrm{mL} ; 24 \mathrm{~h}$ & $\begin{array}{c}\text { Inhibition of breast } \\
\text { cancer cell } \\
\text { invasiveness }\end{array}$ & $\begin{array}{c}\downarrow \text { MMP-9, p-ERK, p-JNK, } \\
\text { p-p38, p-c-Jun }\end{array}$ & [30] \\
\hline $\begin{array}{l}\text { Hepatocellular } \\
\text { carcinoma }\end{array}$ & $\begin{array}{l}\text { Astragalus and Salvia } \\
\text { miltiorrhiza } \\
\text { water/ethanol extract } \\
\text { (71:1.85) }\end{array}$ & $\begin{array}{c}\text { (1) SD rat } \\
\text { (2) TGF- } \beta 1 \text {-stimulated } \\
\text { HepG2 } \\
\text { (3) BALB/c xenograft } \\
\text { mouse model }\end{array}$ & $\begin{array}{c}\text { (1) } 60,120,240 \mathrm{mg} / \mathrm{kg} ; \\
28 \text { days } \\
\text { (2) } 20,40,80 \mu \mathrm{gg} / \mathrm{mL} ; 12 \\
24 \mathrm{~h} \\
\text { (3) } 310 \mathrm{mg} / \mathrm{kg} ; 28 \text { days }\end{array}$ & $\begin{array}{l}\text { Inhibition of } \\
\text { hepatocellular } \\
\text { carcinoma } \\
\text { progression }\end{array}$ & $\begin{array}{c}\uparrow \text { Smad3C, miR-145 } \\
\downarrow \text { Smad3L, miR-21, p-ERK, } \\
\text { p-JNK, p-p38 }\end{array}$ & [31] \\
\hline $\begin{array}{l}\text { Hepatocellular } \\
\text { carcinoma }\end{array}$ & $\begin{array}{l}\text { Astragalus and Salvia } \\
\text { miltiorrhiza } \\
\text { water/ethanol extract } \\
\text { (71:1.85) }\end{array}$ & $\begin{array}{c}\text { (1) SD rat } \\
\text { (2) HSCs, HepG2 }\end{array}$ & $\begin{array}{c}\text { (1) } 60,120,240 \mathrm{mg} / \mathrm{kg} ; 12, \\
16 \text { weeks } \\
\text { (2) } 20,40,80 \mu \mathrm{g} / \mathrm{mL} ; 24 \mathrm{~h}\end{array}$ & $\begin{array}{l}\text { Inhibition of } \\
\text { hepatocellular } \\
\text { carcinoma }\end{array}$ & $\begin{array}{c}\text { (1) } \uparrow \text { pSmad3C } \\
\downarrow \text { p-ERK, p-JNK, p-p38, } \\
\text { pSmad3L, Smad4, Imp 7/8, } \\
\text { PAI-1 } \\
(2) \uparrow \text { p38 } \\
\downarrow \text { p-ERK, p-JNK }\end{array}$ & [32] \\
\hline $\begin{array}{l}\text { Multiple myeloma } \\
\text { and myeloid } \\
\text { leukemia }\end{array}$ & $99.9 \%$ ethanol & U266, U937 & $\begin{array}{c}25,50,100,200 \mu \mathrm{g} / \mathrm{mL} \\
24 \mathrm{~h}\end{array}$ & $\begin{array}{l}\text { Induction of } \\
\text { apoptosis }\end{array}$ & $\begin{array}{c}\uparrow \text { miR-216b, p-ATF4, p-eIf2, } \\
\text { p-PERK, ROS, CHOP, } \\
\text { c-PARP, c-caspase-3 } \\
\downarrow \text { c-Jun }\end{array}$ & [33] \\
\hline $\begin{array}{l}\text { Non-small cell lung } \\
\text { cancer (NSCLC) }\end{array}$ & $\begin{array}{l}\text { Methanol extract } \\
\text { (CTN-compounds of } \\
\text { tanshinone) }\end{array}$ & $\begin{array}{l}\text { (1) Glc-82 } \\
\text { (2) } \mathrm{BALB} / \mathrm{c} \text { mice }\end{array}$ & $\begin{array}{l}\text { (1) } 20,40 \mu \mathrm{g} / \mathrm{mL} ; 24 \mathrm{~h} \\
\text { (2) } 40 \mathrm{mg} ; 22 \text { days }\end{array}$ & $\begin{array}{l}\text { Induction of } \\
\text { apoptosis }\end{array}$ & $\begin{array}{c}\uparrow \text { p53, p21, c-caspase-3, -9, } \\
\text { c-PARP1, PTEN, Bax } \\
\downarrow \text { Bcl-2, Bcl-xl, p-Akt }\end{array}$ & [34] \\
\hline $\begin{array}{l}\text { Non-small cell lung } \\
\text { cancer (NSCLC) }\end{array}$ & $\begin{array}{l}\text { Oldenlandia diffusa, } \\
\text { Salvia miltiorrhiza } 50 \% \\
\text { EtOH extract }(5: 2)\end{array}$ & $\begin{array}{c}\text { (1) A549, H460 } \\
\text { (2) HUVECs } \\
\text { (3) H460 xenograft model }\end{array}$ & $\begin{array}{c}(1,2) \text { PR } 2.5 \mu \mathrm{g} / \mathrm{mL}+\text { OS } \\
180 \mu \mathrm{g} / \mathrm{mL} ; 24 \mathrm{~h} \\
\text { (3) PR } 125 \mu \mathrm{g} / \mathrm{kg}+\text { OS } 20 \\
\mathrm{mg} / \mathrm{kg} ; 18 \text { days }\end{array}$ & $\begin{array}{l}\text { Antiangiogenic and } \\
\text { apoptotic effects }\end{array}$ & $\begin{array}{c}\uparrow \text { c-caspase-3 } \\
\downarrow \text { p-STAT3, pro-PARP, Bcl-2, } \\
\text { cyclin E, cyclin A, CDK2, } \\
\text { E2F1, p-ERK, p-Akt, COX-2, } \\
\text { SOCS-1, p-Src, VEGF, } \\
\text { p-VEGFR2 }\end{array}$ & [35] \\
\hline Oral cancer & $\begin{array}{c}\text { Double-distilled water, } \\
95 \% \text { ethanol or 1:1 } \\
\text { water/ethanol }\end{array}$ & $\begin{array}{l}\text { (1) HSC-3, OC-2 } \\
\text { (2) BALB/cNU mice }\end{array}$ & $\begin{array}{c}\text { (1) } 10,25,50 \mu \mathrm{g} / \mathrm{mL} ; 48 \\
72 \mathrm{~h} \\
\text { (2) } 50,100 \mathrm{mg} / \mathrm{kg} ; 34 \text { days }\end{array}$ & $\begin{array}{l}\text { Inhibition of oral } \\
\text { squamous carcinoma } \\
\text { cell proliferation }\end{array}$ & $\begin{array}{c}\uparrow \text { c-caspase-3 } \\
\downarrow \text { XIAP, survivin }\end{array}$ & [36] \\
\hline
\end{tabular}


Table 1. Cont.

\begin{tabular}{|c|c|c|c|c|c|c|}
\hline Disease & Extract & Experimental Model & Dose; Duration & Efficacy & Mechanism & Reference \\
\hline Oral cancer & $95 \%$ ethanol & $\begin{array}{l}\text { (1) SAS, SCC25, Oec-ml } \\
\text { (2) KB, KB7D, KB tax, } \\
\text { KB100, KB Vin, KB Vin } 10 \\
\text { (3) SAS xenograft } \\
\text { animal model }\end{array}$ & $\begin{array}{c}\text { (1) } 0.625,1.25,2.5,5,10 \\
20,30 \mu \mathrm{g} / \mathrm{mL} ; 24 \mathrm{~h} \\
\text { (2) } 2.5,5,10,20,40,80 \\
\mu \mathrm{g} / \mathrm{mL} ; 24 \mathrm{~h} \\
\text { (3) } 10 \mathrm{mg} / \mathrm{kg} ; 32 \text { days }\end{array}$ & $\begin{array}{l}\text { Inhibition of } \\
\text { proliferation of oral } \\
\text { cancer cell }\end{array}$ & $\begin{array}{c}\uparrow \text { c-caspase-3 } \\
\downarrow \text { XIAP }\end{array}$ & {$[37]$} \\
\hline Prostate cancer & Acetonitrile & $\begin{array}{c}\text { (1) PC-3 } \\
\text { (2) PC-3 xenograft } \\
\text { mouse model }\end{array}$ & $\begin{array}{l}\text { (1) } 20 \mu \mathrm{g} / \mathrm{mL} ; 24,48,72 \mathrm{~h} \\
\text { (2) } 100 \mathrm{mg} / \mathrm{kg} ; 6 \text { weeks }\end{array}$ & $\begin{array}{l}\text { Inhibitory effect on } \\
\text { the growth of prostate } \\
\text { cancer cell }\end{array}$ & $\begin{array}{c}\uparrow \text { ROS, c-caspase-3, -9, } \\
\text { c-PARP, p21 } \\
\downarrow \text { Bcl-2, CDK2, CDK4, } \\
\text { cyclin D1 }\end{array}$ & [38] \\
\hline Various cancers & $\begin{array}{l}100 \% \text { ethanol or } \\
100 \% \text { acetone }\end{array}$ & $\begin{array}{l}\text { AGS, A549, HCT116, } \\
\text { LNCaP, MCF7 }\end{array}$ & $5,10,20,40 \mu \mathrm{g} / \mathrm{mL} ; 24 \mathrm{~h}$ & $\begin{array}{c}\text { Inhibitory effect on } \\
\text { the growth of } \\
\text { cancer cells }\end{array}$ & & [39] \\
\hline $\begin{array}{l}\text { Multidrug-resistant } \\
\text { cancer }\end{array}$ & $\begin{array}{c}\text { Dichloromethane-methanol } \\
(1: 1)\end{array}$ & CCRF-CEM & $\begin{array}{c}\text { (1) } 3,10,30 \mu \mathrm{g} / \mathrm{mL} ; 1 \mathrm{~h} \\
\text { (2) } 5,10,20,40 \mu \mathrm{g} / \mathrm{mL} \text {; } \\
\text { N/A } \\
\text { (3) } 20 \mu \mathrm{g} / \mathrm{mL} ; 24,2 \mathrm{~h}\end{array}$ & $\begin{array}{l}\text { Cytotoxicity towards } \\
\text { multidrug-resistant } \\
\text { cancer cells }\end{array}$ & $\begin{array}{c}\uparrow \text { ROS, p-JNK, p-ERK1/2, } \\
\text { p-p38, c-caspase-3, -7, -9, } \\
\text { c-PARP } \\
\downarrow \text { p65 translocation }\end{array}$ & [40] \\
\hline
\end{tabular}

MMP-9, matrix metalloproteinase-9; MAPK, mitogen-activated protein kinase; AP-1, activator protein-1; SD, Sprague Dawley; TGF- $\beta$, transforming growth factor- $\beta$; miR-145, microRNA-145; miR-21, microRNA-21; p-ERK, phospho-extracellular-signal-regulated-kinase; p-JNK, phospho-c-Jun N terminal kinase; p-p38, phosho-p38; HSCs, hepatic stellate cells; Imp, importins; PAI-1, plasminogen activator inhibitor 1; p-ATF4, phospho-activating transcription factor 4; p-eIF2, phospho-eukaryotic initiation factor 2; p-PERK, phospho-protein kinase RNA-like endoplasmic reticulum kinase; CHOP, CCAAT-enhancer-binding protein homologous protein; c-PARP, cleaved poly ADP-ribose polymerase; c-caspase-3, cleaved caspase-3; CTN, compounds of tanshinone; PTEN, phosphatase and tensin homolog deleted on chromosome ten; Bax, Bcl-2 associated X-protein; Bcl-2, B-cell lymphoma 2; Bcl-xl, B-cell lymphoma-extra large; p-Akt, phospho-Akt (protein kinase B); HUVEC, human umbilical vein endothelial cell; PR, tetraarsenic hexoxide; OS, Olendlandia diffusa and Salvia miltiorrhiza extract; p-STAT3, phospho-signal transducer and activator of transcription 3 (Tyr705); VEGF, vascular endothelial growth factor; CDK, cyclin-dependent kinase; XIAP, X-linked inhibitor of apoptosis protein; ROS, reactive oxygen species. 


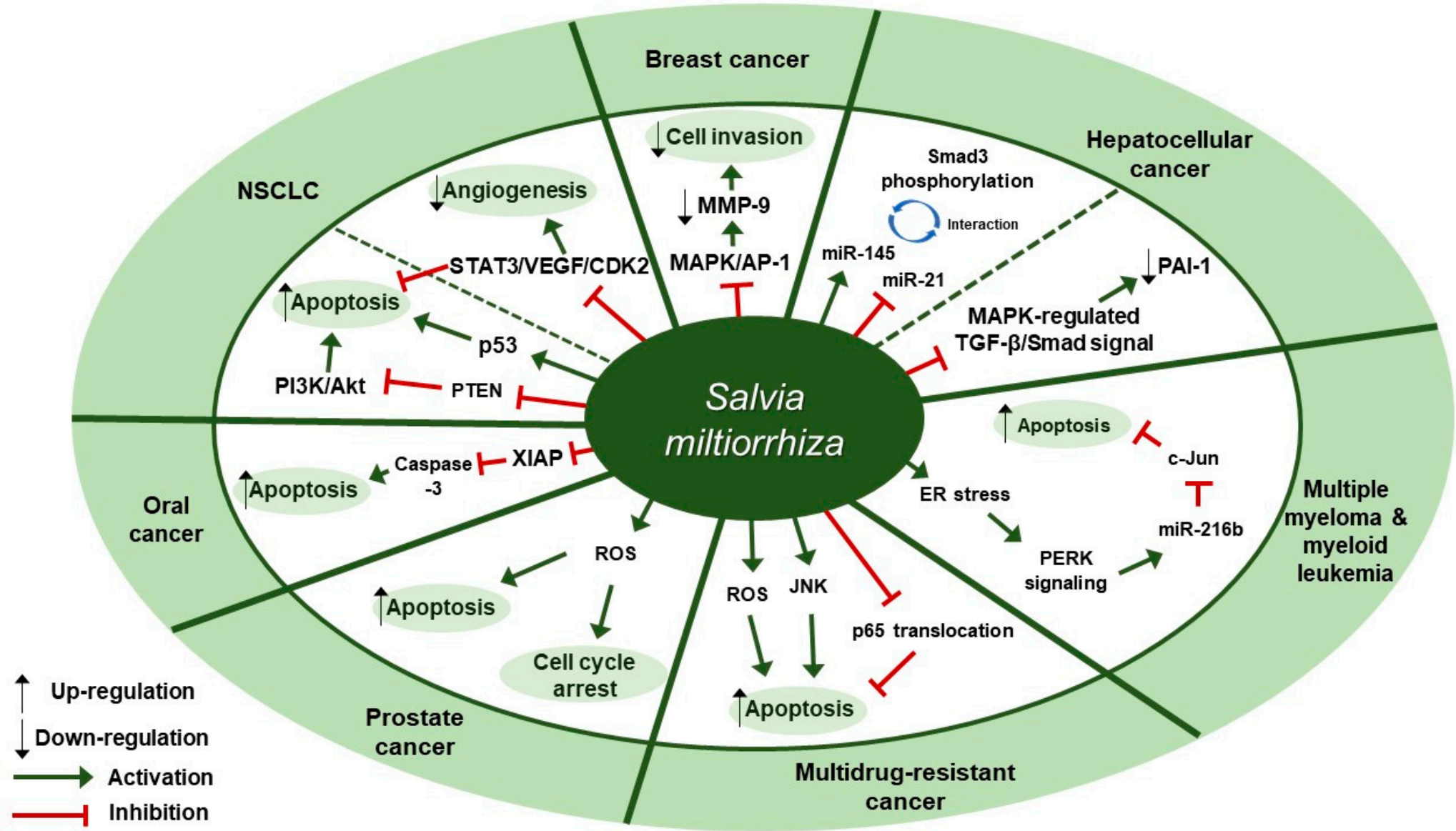

Figure 1. Therapeutic targets of S. miltiorrhiza in cancers. NSCLC, non-small cell lung cancer; MAPK, mitogen-activated protein kinase; AP-1, activator protein-1; MMP-9, matrix metalloproteinase-9; miR-145, microRNA-145; miR-21, microRNA-21; PAI-1, plasminogen activator inhibitor 1; ER, endoplasmic reticulum; PERK, protein kinase RNA-like endoplasmic reticulum kinase; miR-216b, microRNA-216b; JNK, c-Jun N-terminal kinase; ROS, reactive oxygen species; XIAP, X-linked inhibitor of apoptosis protein; PTEN, phosphatase and tensin homolog deleted on chromosome ten; PI3K, phosphoinositide 3-kinase; NSCLC, non-small cell lung cancer; STAT3, signal transducer and activator of transcription 3; VEGF, vascular endothelial growth factor; CDK2, cyclin-dependent kinase 2. 


\section{Cardiovascular Diseases}

Cardiovascular disease (CVD) is the leading cause of mortality worldwide [41]. In 2017, CVD claimed 17.8 million lives globally, which was an increase of $21.1 \%$ from 2007 . The global burden of CVD can be attributed to risk factors such as dietary risks, high systolic blood pressure, high body mass index, high total cholesterol level, high fasting plasma glucose level, tobacco smoking, and low levels of physical activity [42]. CVD includes all diseases and conditions of the heart and the blood vessels, but we here focus on ischemic heart disease (International Classification of Diseases (ICD): I20-25) and other forms of heart disease (ICD: I30-I52). The ischemic heart disease, also known as coronary heart disease, accounted for $49 \%$ of total global CVD burden in 2016 [43]. The clinical condition of ischemic heart disease includes angina, myocardial infarction, sudden death, and consequent chronic heart failure [44]. Among them, myocardial infarction (MI) is defined clinically as the presence of acute myocardial injury detected by abnormal cardiac biomarkers (i.e., cardiac troponin value above the 99th percentile upper reference limit) in the setting of evidence of acute myocardial ischemia; pathologically as myocardial cell death due to prolonged ischemia [45]. Prolonged ischemic condition leads to tremendous sudden death of cardiomyocytes primarily through cell necrosis, with partial involvement of apoptosis [46]. Necrotic cells and the damaged extracellular matrix tissue release danger signals, initiating an intense inflammatory response. Suppression and resolution of the inflammation, which are partly mediated by anti-inflammatory and pro-fibrotic cytokines (such as IL-10 and TGF- $\beta_{1}$ ), are critical for optimal wound healing; dysregulation of them, in combination with overactive myocardial fibrosis, contribute to the pathogenesis of adverse left ventricular (LV) remodeling and eventually heart failure (HF) after MI [47].

\section{Cardiovascular Diseases and S. miltiorrhiza}

Several studies about protective effects of S. miltiorrhiza against cardiovascular diseases have been reported (Table 2). Liu et al. reported in a clinical trial that 3-month administration of Danshen pills, which were prepared from the extracts of $S$. miltiorrhiza and provided as $27 \mathrm{mg} /$ pill, could lessen the chance of the coronary heart disease (CHD) risk by enhancing the biochemical indices of CHD patients [48]. Changes in the biochemical indices associated with CHD risk were assessed, such as lipid profile values (total cholesterol [TC], triglycerides [TG], low-density lipoprotein cholesterol [LDL-C], and high-density lipoprotein cholesterol [HDL-C]), apolipoproteins (ApoA, ApoB, and ApoE), lipoprotein $(a)(\mathrm{Lp}(\mathrm{a}))$, and markers of liver ( $\gamma$-glutamyl transpeptidase [GGT], direct bilirubin [DBil], and indirect bilirubin [IBil]) and renal function (uric acid [UA] and homocysteine [Hcy]). The patients in the Danshen group received $10 \mathrm{~S}$. miltiorrhiza pills three times a day for 3 months after three-month run-in period, whereas the control patients received placebo pills. At three-month follow-up, the Danshen group showed decreased levels of TC, TG, LDL-C, Lp(a), GGT, DBil, UA, and Hcy; on the contrary, they displayed increased levels of HDL-C, ApoA, ApoB, ApoE, TBil, and IBil. Zhang et al. examined the protective effect of $S$. miltiorrhiza injection against cardiac fibrosis induced by chronic iron overload (CIO) in mice [49]. Intraperitoneal injection of S. miltiorrhiza at doses of 3 or $6 \mathrm{~g} / \mathrm{kg}$ decreased the heart weight-body weight coefficients, iron deposition levels, fibrotic area percentage, and hydroxyproline (Hyp) content. Further, S. miltiorrhiza injection reversed the changes in oxidative stress markers such as superoxide dismutase (SOD) activity and malondialdehyde (MDA) concentration. S. miltiorrhiza injection also dose-dependently lowered the protein expression levels of COL I, COL III, TGF- $\beta_{1}$, and MMP-9. According to Ai et al., intraperitoneal S. miltiorrhiza injection at doses of $3 \mathrm{or} 6 \mathrm{~g} / \mathrm{kg}$ per day for 4 weeks had beneficial effects on impaired cardiac angiogenesis in a rat model of myocardial infarction via up-regulation of expression of key proangiogenic factors, hypoxia-inducible factor $1 \alpha$ (HIF1 $\alpha$ ) and vascular endothelial growth factor A (VEGFA) [50]. S. miltiorrhiza injection also improved ejection fraction (EF) and fractional shortening (FS), indicating its cardiac function-improving effect. Wang et al. showed that intramuscular administration of Danshen injection (DSI) at a dose of $1.5 \mathrm{~mL} / \mathrm{kg} / \mathrm{d}$ for 14 days could prevent left ventricular remodeling in a mouse model of heart failure induced by left anterior descending coronary artery (LAD) ligation [51]. DSI administration improved 
cardiac function as assessed by echocardiography parameters such as left ventricular ejection fraction (EF) and fractional shortening (FS); improved hemodynamic parameters (the maximum rate of LV pressure rise $(\mathrm{dP} / \mathrm{dt} \max )$ and fall (-dP/dt max), left ventricular end-diastolic pressure [LVEDP], volumes-related stroke volume, and cardiac output) and restored regular ventricular mass in a rat model of left anterior descending (LAD) coronary artery ligation. Further, DSI administration down-regulated MMP-2 protein expression, MMP-9, myeloperoxidase (MPO) and inducible nitric oxide synthase (iNOS) mRNA expression, indicating its anti-inflammatory effect; in contrast, DSI increased Bcl-2/Bax ratio, implying its anti-apoptotic effect. Yang et al. found that intraperitoneal administration of S. miltiorrhiza and Carthamus tinctorius extract (SCE) at a dose of $3 \mu \mathrm{L} / \mathrm{g} /$ day for 3 weeks attenuated cardiac dysfunction and myocardial fibrosis in a mouse model of LAD ligation [52]. Furthermore, SCE administration suppressed myocardial infarction (MI)-induced inflammation, as shown by the

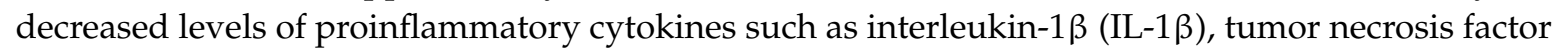
(TNF), and interleukin-6 (IL-6), and the increased levels of anti-inflammatory cytokine interleukin-10 (IL-10). In vivo administration of SCE also had an inhibitory effect on the mRNA expression levels of fibrosis-related genes, such as collagen type I alpha 1 (Col1a1), collagen type III alpha 1 (Col3a1), actin alpha 2 (Acta2), and the expression levels of the proteins encoded by these genes, including type I collagen (COL I), COL III, and $\alpha$-smooth muscle actin (SMA), respectively, which indicated SCE-induced attenuation of myocardial fibrosis in mice after MI. Further, they screened the proteins implicated in the TGF-dependent pathway and it turned out Smad3 in the SMAD family was suppressed by SCE administration. In vitro, SCE treatment reduced the TGF- $\beta$-induced increase in $\mathrm{H} 3 \mathrm{~K} 4$ trimethylation $(\mathrm{H} 3 \mathrm{~K} 4 \mathrm{me} 3)$ and $\mathrm{H} 3 \mathrm{~K} 36$ trimethylation $(\mathrm{H} 3 \mathrm{k} 36 \mathrm{me} 3)$ at the Smad3 promoter region of cardiac fibroblasts, which led to decreased transcription of Smad3. Mao et al. demonstrated the extract of S. miltiorrhiza and its mixture with Astragalus mongholicus could inhibit myocardial fibrosis and ventricular remodeling by the regulation of protein kinase D1 (PKD1) protein in a rat model of myocardial infarction [53]. Oral administration of $S$. miltiorrhiza extract, alone or in combination with Astragalus mongholicus extract, at a dose of $20 \mathrm{mg} / \mathrm{kg}$ once a day for 8 weeks resulted in the improvement in systolic and diastolic functions as shown by the increased levels of left ventricular systolic pressure (LVSP), LVEDP, and $\pm \mathrm{dP} / \mathrm{dt}$ max; the maintenance of normal morphology and arrangement of cardiomyocytes as assessed by hematoxylin-eosin (H\&E) staining; the reduction in contents of collagen fibers in myocardial tissues as evaluated by Masson's trichrome staining; and the decreased expression level of protein kinase D1 (PKD1) as compared with the control group. Interestingly, combination of extracts of S. miltiorrhiza and Astragalus mongholicus led to better results as compared to the single use of either S. miltiorrhiza or Astragalus mongholicus extract. Wang et al. investigated the regulatory effect of the Danqi pill (DQP), which was prepared from water extracts of S. miltiorrhiza and Panax notoginseng, on MI-induced lipid metabolism disorder through activating fatty acids transport protein (FATP)-carnitine palmitoyltransferase I (CPTI) pathway and attenuating the inhibitory effect of nuclear receptor subfamily 2 group $\mathrm{C}$ member 2 (NR2C2) on peroxisome proliferator-activated receptor $\alpha($ PPAR $\alpha)$-retinoid $X$ receptor (RXR) pathway [54]. Oral administration of DQP at a dose of $1.5 \mathrm{mg} / \mathrm{kg}$ for 28 days in a SD rats model of myocardial ischemia improved cardiac function-related parameters, such as EF, FS, and left ventricular end-systolic diameter (LVEDs); decreased the levels of TG, LDL, ApoB, and hydroxy-3-methyl glutaryl coenzyme A reductase (HMGCR); and increased the levels of ApoA-I, cardiac FATP, and CPTI. Besides, DQP administration up-regulated PPAR $\alpha$-RXR pathway, as shown by the increased protein expression of PPAR $\alpha$ and RXRs as well as the decreased protein expression of NR2C2. Ma et al. demonstrated that Danqi soft capsule (DQ), which was prepared from powdered water extracts of S. miltiorrhiza and Panax notoginseng, could inhibit infarct border zone (IBZ) remodeling and reduce susceptibility to ventricular tachyarrhythmias (VT) possibly via TGF- $\beta_{1} / \mathrm{Smad}_{3}$ pathway in a rat model of post-myocardial infarction [55]. Oral administration of DQ at doses of 0.6, 0.9 , or $1.2 \mathrm{~g} / \mathrm{kg}$ for 4 weeks inhibited cardiac fibrosis in the IBZ as shown by the reduction in COL I and COL III expression levels; reversed Cx43 expression and distribution in the IBZ as assessed by Western blot and immunohistochemical staining; and prevented MI-induced myocyte hypertrophy 
in the IBZ as evidenced by the decreased mRNA expression levels of the hypertrophic marker atrial natriuretic peptide (ANP). Besides, DQ administration suppressed fibroblasts differentiation into myofibroblasts; it resulted in the decreased protein levels of $\alpha$-SMA, TGF- $\beta_{1}$, and p-Smad3. It also decreased the serum levels of brain natriuretic peptide (BNP), monocyte chemoattractant protein (MCP)- 1 and TGF- $\beta_{1}$. Xu et al. reported that $75 \%$ ethanol extraction of $S$. miltiorrhiza $\left(\mathrm{IC}_{50}=86.5 \mu \mathrm{g} / \mathrm{mL}\right)$ could exert its cardiovascular protective and anti-inflammatory effects through inhibiting the activity of soluble epoxide hydrolase (sEH), a proinflammatory enzyme that converts its physiological substrate epoxyeicosatrienoic acids (EETs) to the less active dihydroxyeicosatrienoic acids (DHETs) [56]. They also tested which components of S. miltiorrhiza contributed to sEH inhibition based on a LC-MS/MS assay and discovered that tanshinone IIA and cryptotanshinone were potent (the inhibition constant $\left.\left[\mathrm{K}_{\mathrm{i}}\right]=0.87 \mu \mathrm{M}\right)$ and medium $\left(\mathrm{K}_{\mathrm{i}}=6.7 \mu \mathrm{M}\right)$ mixed-type inhibitors of $s E H$, respectively, and Salvianolic acid $\mathrm{C}$ was a moderate $\left(\mathrm{K}_{\mathrm{i}}=8.6 \mu \mathrm{M}\right)$ noncompetitive inhibitor of $\mathrm{sEH}$. Huang et al. showed S. miltiorrhiza and ligustrazine injection (SLI), prepared in a proportion of 1.2:60, had a beneficial effect on myocardial ischemia/reperfusion (I/R) and hypoxia/reoxygenation $(\mathrm{H} / \mathrm{R})$ injuries in mice subjected to coronary artery occlusion and $2 \mathrm{~h}$ reperfusion via Akt serine/threonine kinase (Akt)-endothelial nitric oxide synthase (eNOS) signaling pathway [57]. In vivo pretreatment with SLI at doses of $6.8,20.4$, or $61.2 \mathrm{mg} / \mathrm{kg}$ daily for 3 days improved cardiac function as illustrated by the increased LVSP and $+\mathrm{dP} / \mathrm{dt}$ max, reduced the size of myocardial infarct, and mitigated the changes in myocardial histopathology. Besides, it decreased the blood serum levels of creatine kinase (CK), lactate dehydrogenase (LDH), and malondialdehyde (MDA) and increased the superoxide dismutase (SOD) levels. After in vitro treatment of $\mathrm{H} 9 \mathrm{C} 2$ cells with SLI, apoptosis was inhibited, as evidenced by the decreased caspase-3 expression level and the increased Bcl-2/Bax ratio. Further, SLI pretreatment increased the phosphorylation of the survival kinase Akt at Ser473 and its downstream target eNOS following H/R. Therapeutic targets of S. miltiorrhiza in cardiovascular diseases are demonstrated in Figure 2. 
Table 2. Cardiovascular diseases and S. miltiorrhiza.

\begin{tabular}{|c|c|c|c|c|c|c|}
\hline Disease & Extract & Experimental Model & Dose; Duration & Efficacy & Mechanism & Reference \\
\hline $\begin{array}{c}\text { Coronary heart disease } \\
\text { (CHD) }\end{array}$ & $\begin{array}{c}\text { Extractant } \\
\text { unmentioned } \\
\text { (Danshen pills) }\end{array}$ & Patients & $810 \mathrm{mg} /$ day; 3 months & $\begin{array}{l}\text { Reduction of the } \\
\text { CHD risk }\end{array}$ & $\begin{array}{c}\uparrow \text { HDL-C, ApoA, ApoB, } \\
\text { ApoE, TBil, IBil } \\
\downarrow \text { TG, TC, LDL-C, Lp(a), } \\
\text { GGT, DBil, UA, Hcy }\end{array}$ & [48] \\
\hline $\begin{array}{l}\text { Iron-mediated myocardial } \\
\text { fibrosis }\end{array}$ & Water & Kunming mice & $3,6 \mathrm{~g} / \mathrm{kg} ; 7$ weeks & $\begin{array}{l}\text { Protective effect on } \\
\text { cardiac fibrosis } \\
\text { induced by chronic } \\
\text { iron overload }\end{array}$ & $\begin{array}{c}\uparrow \text { SOD } \\
\downarrow \text { TGF- } \beta_{1}, \text { MMP-9, COL } \\
\text { I, COL III }\end{array}$ & [49] \\
\hline Myocardial infarction (MI) & $\begin{array}{c}\text { Extractant } \\
\text { unmentioned } \\
\text { (Danshen injection) }\end{array}$ & BALA/c mice & $3,6 \mathrm{~g} / \mathrm{kg} ; 4$ weeks & $\begin{array}{l}\text { Beneficial effect on } \\
\text { cardiac angiogenesis } \\
\text { and cardiac function }\end{array}$ & $\uparrow \mathrm{HIF} 1 \alpha, \mathrm{VEGFA}$ & [50] \\
\hline Myocardial infarction (MI) & Water & SD rats & $1.5 \mathrm{~mL} / \mathrm{kg} ; 14$ days & $\begin{array}{l}\text { Anti-inflammatory } \\
\text { and anti-cardiac } \\
\text { remodeling effects }\end{array}$ & $\begin{array}{c}\uparrow \text { Bcl-2/Bax } \\
\downarrow \text { MMP-2, MMP-9, iNOS, } \\
\text { MPO }\end{array}$ & [51] \\
\hline Myocardial infarction (MI) & $\begin{array}{l}\text { Salvia miltiorrhiza } \\
\text { and Carthamus } \\
\text { tinctorius extract } \\
\text { (ratio unmentioned) }\end{array}$ & $\begin{array}{l}\text { Wild-type C57BL/6 } \\
\text { mice }\end{array}$ & $3 \mu \mathrm{L} / \mathrm{g} ; 3$ weeks & $\begin{array}{c}\text { Inhibition of } \\
\text { inflammation and } \\
\text { fibrosis }\end{array}$ & $\begin{array}{c}\uparrow \uparrow \text { IL-10 } \\
\downarrow \text { H3K4me3, H3K36me3, } \\
\text { IL-1 } \beta, \text { TNF, IL-6, COL I, } \\
\text { COL III, } \alpha \text {-SMA, Col1a1, } \\
\text { Col3a1, Acta2 }\end{array}$ & [52] \\
\hline Myocardial infarction (MI) & $\begin{array}{c}\text { Salvia miltiorrhiza } \\
\text { Bunge and } \\
\text { Astragalus } \\
\text { mongholicus extract } \\
(1: 1)\end{array}$ & SD rats & $\begin{array}{c}20 \mathrm{mg} / \mathrm{kg} / \text { day; } 8 \\
\text { weeks }\end{array}$ & $\begin{array}{l}\text { Inhibition of } \\
\text { myocardial fibrosis } \\
\text { and ventricular } \\
\text { remodeling }\end{array}$ & $\downarrow$ PKD1 & [53] \\
\hline Myocardial ischemia & $\begin{array}{l}\text { Salvia miltiorrhiza } \\
\text { Bunge and Panax } \\
\text { notoginseng water } \\
\text { extract (1:1) }\end{array}$ & SD rats & $1.2 \mathrm{mg} / \mathrm{kg} ; 28$ days & $\begin{array}{l}\text { Regulatory effect on } \\
\text { lipid metabolism } \\
\text { disorder induced by } \\
\text { myocardial ischemia }\end{array}$ & $\begin{array}{c}\uparrow \text { ApoA-I, FATP, CPTI, } \\
\text { PPAR } \alpha, \text { RXR } \\
\downarrow \text { TG, LDL, Apo-B, } \\
\text { HMGCR, NR2C2 }\end{array}$ & [54] \\
\hline
\end{tabular}


Table 2. Cont

\begin{tabular}{|c|c|c|c|c|c|c|}
\hline Disease & Extract & Experimental Model & Dose; Duration & Efficacy & Mechanism & Reference \\
\hline Post-MI complications & $\begin{array}{l}\text { Salvia miltiorrhiza } \\
\text { Bunge and Panax } \\
\text { notoginseng } \\
\text { powdered water } \\
\text { extract (1:1) }\end{array}$ & SD rats & $\begin{array}{c}0.6,0.9,1.2 \mathrm{~g} / \mathrm{kg} ; 4 \\
\text { weeks }\end{array}$ & $\begin{array}{l}\text { Inhibition of infarct } \\
\text { border zone } \\
\text { remodeling and } \\
\text { ventricular } \\
\text { arrhythmias }\end{array}$ & $\begin{array}{c}\uparrow \text { Cx43 } \\
\downarrow \text { TGF- } \beta_{1}, \text { COL I, COL III, } \\
\alpha \text {-SMA, p-Smad3, BNP, } \\
\text { MCP-1 }\end{array}$ & [55] \\
\hline $\begin{array}{l}\text { Ischemia-reperfusion injury, } \\
\text { cardiac hypertrophy, } \\
\text { hypertension, and } \\
\text { inflammation }\end{array}$ & $75 \%$ ethanol & sEH, 8,9-EET & $\mathrm{IC}_{50}: 86.5 \mu \mathrm{g} / \mathrm{mL}$ & $\begin{array}{c}\text { Cardiovascular } \\
\text { protective and } \\
\text { anti-inflammatory } \\
\text { effects }\end{array}$ & $\downarrow$ sEH activity, 8,9-DHET & [56] \\
\hline $\begin{array}{c}\text { Myocardial } \\
\text { ischemia/reperfusion }(\mathrm{I} / \mathrm{R}) \\
\text { and hypoxia/reoxygenation } \\
\text { injuries }\end{array}$ & $\begin{array}{l}\text { Salvia miltiorrhiza } \\
\text { and ligustrazine } \\
\text { injection (1:50) }\end{array}$ & SD rats & $\begin{array}{c}6.8,20.4,61.2 \\
\mathrm{mg} / \mathrm{kg} / \mathrm{day} ; 3 \text { days }\end{array}$ & $\begin{array}{c}\text { Alleviation of I/R } \\
\text { injury in } \\
\text { cardiomyocytes and } \\
\text { inhibition of } \\
\text { apoptosis }\end{array}$ & $\begin{array}{c}\uparrow \text { Bcl-2/Bax, p-Akt, } \\
\text { p-eNOS, SOD } \\
\downarrow \text { caspase-3, MDA }\end{array}$ & [57] \\
\hline \multicolumn{7}{|c|}{$\begin{array}{l}\text { HDL-C, high-density lipoprotein cholesterol; ApoA, apolipoprotein A; ApoB, apolipoprotein B; ApoE, apolipoprotein E; TBil, total bilirubin; IBil, indirect bilirubin; TG, triglyceride } \\
\text { TC, total cholesterol; LDL-C, low-density lipoprotein cholesterol; Lp(a), lipoprotein (a); GGT, gamma-glutamyl transpeptidase; DBil, direct bilirubin; UA, uric acid; Hcy, homocystein } \\
\text { SOD, superoxide dismutase; Hyp, hydroxyproline; TGF- } \beta 1 \text {, transforming growth factor- } \beta 1 \text {; MDA, malondialdehyde; MMP, matrix metalloproteinase; COL I, type I collagen; COL II } \\
\text { type III collagen; HIF1 } \alpha \text {, hypoxia-inducible factor } 1 \alpha \text {; SD, Sprague Dawley; VEGFA, vascular endothelial growth factor A; Bcl-2, B-cell lymphoma 2; Bax, Bcl-2 associated X protei } \\
\text { iNOS, inducible nitric oxide synthase; MPO, myeloperoxidase; IL-10, interleukin-10; H3K4me3, H3K4 trimethylation; H3K36me3, H3K36 trimethylation; IL-1 } \beta \text {, interleukin-1 } \beta \text {; TN } \\
\text { tumor necrosis factor; IL-6, interleukin-6; } \alpha \text {-SMA, } \alpha \text {-smooth muscle actin; Col1a1, collagen type I alpha 1; Col3a1, collagen type } 3 \text { alpha } 1 \text {; Acta2, actin alpha 2; PKD1, protein kinas } \\
\text { D1 protein; FATP, fatty acids transport protein; CPTI, carnitine palmitoyltransferase I; PPAR } \alpha \text {, peroxisome proliferator-activated receptor- } \alpha \text {; RXR, retinoid X receptor; HMGCI } \\
\text { 3-hydroxy-3-methylglutaryl-coenzyme A reductase; NR2C2, nuclear receptor subfamily 2 group C member 2; Cx43, connexin 43; p-Smad3, phospho-Smad3; BNP, brain natriuretic peptid } \\
\text { MCP-1, monocyte chemoattractant protein-1; sEH, soluble epoxide hydrolase; 8,9-EET, 8,9-epoxyeicosatrienoic acid; 8,9-DHET, 8,9-dihydroxyeicosatrienoic acids; p-Akt; phospho-Ak } \\
\text { (protein kinase B); p-eNOS, phospho-endothelial nitric oxide synthase. }\end{array}$} \\
\hline
\end{tabular}




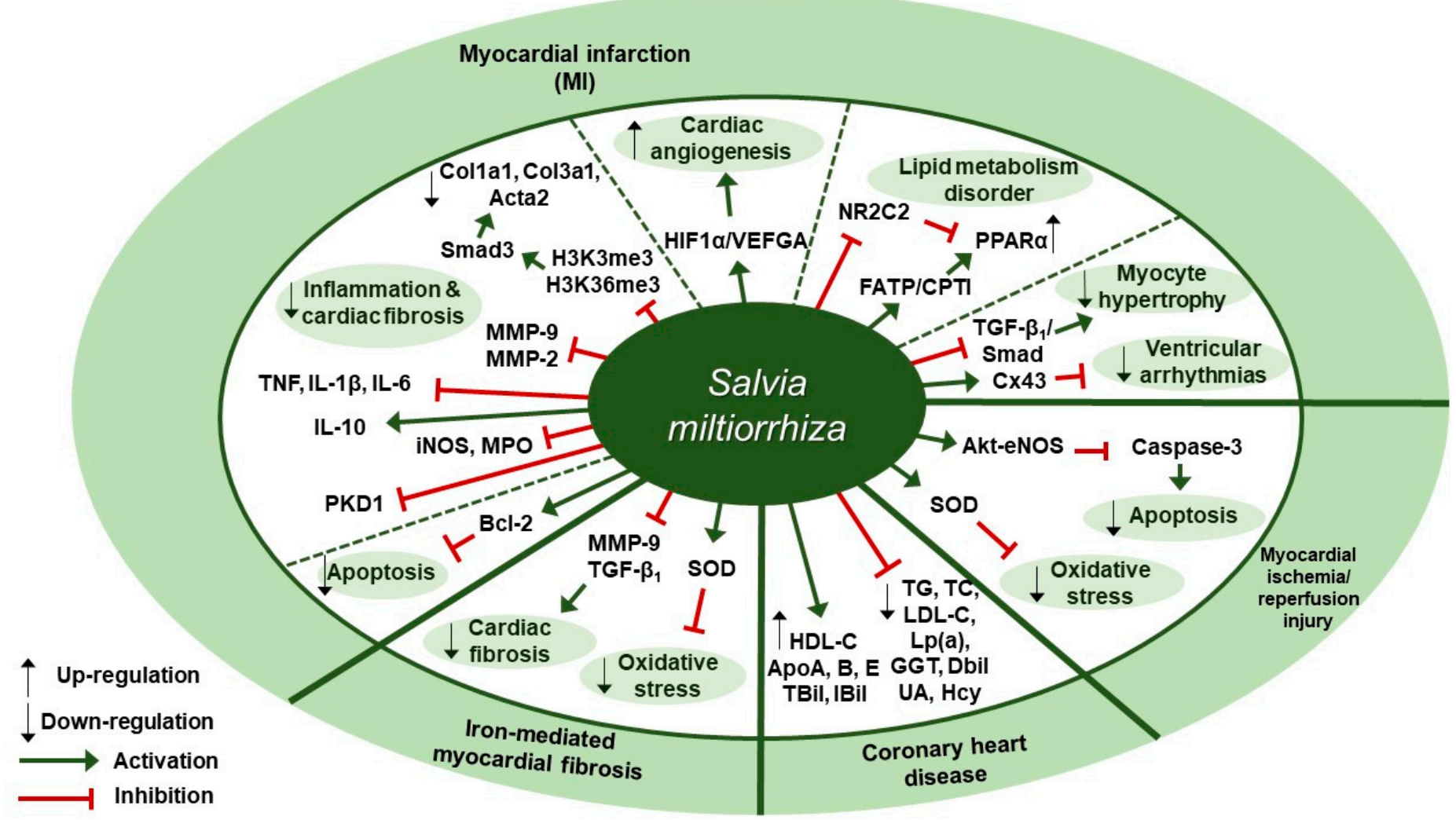

Figure 2. Therapeutic targets of S. miltiorrhiza in cardiovascular diseases. HIF1 $\alpha$, hypoxia-inducible factor 1 $\alpha$; VEGFA, vascular endothelial growth factor A; NR2C2, nuclear receptor subfamily 2 group C member 2; FATP, fatty acids transport protein; CPTI, carnitine palmitoyltransferase I; PPAR $\alpha$, peroxisome proliferator-activated receptor- $\alpha$; Cx43, connexin 43; eNOS, endothelial nitric oxide synthase; SOD, superoxide dismutase; TG, triglycerides; TC, total cholesterol; LDL-C, low-density lipoprotein cholesterol; Lp(a), lipoprotein (a); GGT, gamma-glutamyl transpeptidase; DBil, direct bilirubin; UA, uric acid; Hcy, homocysteine; HDL-C, high-density lipoprotein cholesterol; ApoA, apolipoprotein A; TBil, total bilirubin; IBil, indirect bilirubin; MMP, matrix metalloproteinase; Bcl-2, B-cell lymphoma 2; PKD1, protein kinase D1 protein; iNOS, inducible nitric oxide synthase; MPO, myeloperoxidase; IL-10, interleukin-10; TNF, tumor necrosis factor; IL-1 $\beta$, interleukin-1 $\beta$; IL-6, interleukin-6; H3K4me3, H3K4 trimethylation; H3K36me3, H3K36 trimethylation; Col1a1, collagen type I alpha 1, Col3a1, collagen type III alpha 1; Acta2, actin alpha 2. 


\section{Liver Diseases}

When it comes to liver diseases, heavy alcohol consumption plays an important role in the occurrence of pathological conditions of the liver, such as steatohepatitis and liver fibrosis [58], while such conditions can also occur very commonly in non-alcoholic patients [59]. Alcoholic liver disease (ALD) and non-alcoholic fatty liver disease (NAFLD) are currently the most common etiologies of chronic liver disease (CLD) in the Western world, and their prevalence both are increasing worldwide [60]. Besides, the increasing alcohol misuse and prevalence of obesity and metabolic syndrome are raising the global burden of CLD [61]. ALD can be divided into 4 histological stages: steatosis, steatohepatitis, fibrosis not amounting to cirrhosis, and cirrhosis; progression to cirrhosis is most common in steatohepatitis (10\% per year), followed by fibrosis ( $8 \%$ ) and steatosis ( $3 \%$ ). Mortality in hospitalized patients with steatohepatitis turned out to be even higher than that with cirrhosis, implying the need to treat the disease as high risk in an inpatient setting [62]. On the other hand, NAFLD encompasses two distinct conditions, one of which is non-alcoholic fatty liver (NAFL) and the other is non-alcoholic steatohepatitis (NASH); the latter includes diseases of varying severity, including fibrosis, cirrhosis, and hepatocellular carcinoma (HCC) [63]. Although there has been extensive research on understanding the pathophysiology of the diseases, a proven effective treatment for either ALD or NAFLD is yet to be found. Basically, the treatment strategy for ALD includes alcohol abstinence, nutritional support, steroids, anti-TNF therapy, antioxidants, and liver transplantation; for NAFLD, lifestyle changes (e.g., weight loss, dietary changes, and exercise), insulin sensitizers, lipid lowering agents, antioxidants, and anti-inflammatory agents [64].

\section{Liver Diseases and S. miltiorrhiza}

Several studies about therapeutic effects of $S$. miltiorrhiza in liver diseases have been reported (Table 3). Ding et al. presented experimental evidence for the protective effect of Danshen injection (DSI) on alcoholic liver disease (ALD) through the activation of peroxisome proliferator-activated receptor alpha (PPAR $\alpha$ ) and subsequent induction of 4-hydroxynonenal (4-HNE) degradation [65]. Intraperitoneal administration of DSI at a dose of $3 \mathrm{~g} / \mathrm{kg}$ daily for 4 weeks in a mouse model of ALD induced by 5 -week ethanol-containing diet attenuated pathological changes of liver as assessed by plasma ALT levels, hepatic triglyceride contents, and liver weight. DSI increased the protein and mRNA expression of PPAR $\alpha$ and the mRNA expression of its downstream target genes carnitine palmitoyltransferase 1 (CPT-1) and CPT-2 in liver tissues of mice. They further discovered that the hepatoprotective effect of DSI was associated with 4-HNE degradation which was mediated by PPAR- $\alpha$ activation by DSI. In vitro pretreatment with DSI at doses of 100 or $200 \mu \mathrm{g} / \mathrm{mL}$ for $2 \mathrm{~h}$ inhibited 4-HNE-induced cell death in HepG2 cells, as evidenced by the reduced LDH release. In addition, treatment of NCTC1469 cells with $150 \mu \mathrm{g} / \mathrm{mL}$ of DSI for $2 \mathrm{~h}$ resulted in reduced intracellular 4-HNE accumulation after exogenous 4-HNE exposure, whereas pretreatment with GW6471, a PPAR $\alpha$ antagonist, abolished the inhibitory effect of DSI on 4-HNE accumulation. Li et al. showed that a herbal mixture extract PSSS composed of Pueraria lobata (40\%), S. miltiorrhiza (25\%), Schisandra chinensis (20\%), and Silybum marianum (15\%) had beneficial effect on alcoholic liver fibrosis (ALF) in rats possibly via the TGF- $\beta_{1} /$ Smad signaling pathway [66]. Sprague Dawley (SD) rats were treated with PSSS at doses of $0.333,0.667$, or $1 \mathrm{~g} / \mathrm{kg}$ for 30 days after fed with Lieber-Decarli alcohol liquid diet and CCl4 injection. PSSS treatment improved histopathological lesions in the liver and decreased the serum levels of liver fibrosis indicators (hyaluronan [HA], laminin [LM], and hydroxyproline [67]). Further, the decreased expression of hepatic MMP-13 and the increased expression of hepatic tissue inhibitor of metalloproteinase (TIMP)-1 was reversed by PSSS administration in mice. It also down-regulated TGF- $\beta_{1}$ protein expression at doses of 0.667 or $1 \mathrm{~g} / \mathrm{kg}$ and protein and mRNA expression of $\mathrm{p}-\mathrm{Smad} 2$ and p-Smad3 at all three doses, whereas it up-regulated Smad7 protein expression at all three doses. Zhou et al. found that treatment with $S$. miltiorrhiza extract could inhibit acetaminophen (APAP)-induced hepatotoxicity through its antioxidant activity and inhibition of cytochrome P450 family 2 subfamily E member 1 (CYP2E1) [68]. One hour of S. miltiorrhiza extract pretreatment enhanced 
cell viability in APAP-stimulated primary SD rat hepatocytes at doses of 0.25 and $1 \mathrm{mg} / \mathrm{mL}$, as shown by 5.6-fold increase in the half maximal effective concentration $\left(\mathrm{EC}_{50}>40 \mathrm{mM}\right)$ which was detected in MTT assay. In the alamar blue assay, S. miltiorrhiza extract $\left(\mathrm{EC}_{50}=40.61 \pm 6.82 \mathrm{mM}\right)$ increased the mitochondrial metabolic activity by 5.3-fold. Further, $S$. miltiorrhiza extract $\left(\mathrm{IC}_{50}=1.07 \mathrm{mg} / \mathrm{mL}\right)$ concentration dependently inhibited CYP2E1-mediated formation of 6-hydroxy-chlorzoxazone in SD rat liver microsomes and turned out to be a mixed type inhibitor of CYP2E1. Besides, in vitro treatment with $S$. miltiorrhiza extract at a dose of $1 \mathrm{mg} / \mathrm{mL}$ exerted an antioxidant effect in rat hepatocytes, as can be seen by the fact that it prevented the depletion of total glutathione (total GSH) induced by 24-h APAP treatment and that it increased the level of glutathione/glutathione disulfide ratio (GSH/GSSG ratio) even higher than $1 \mathrm{mM} \mathrm{N}$-acetyl-cysteine (NAC), the positive control. Yang et al. showed that S. miltiorrhiza at doses of 100 or $200 \mathrm{mg} / \mathrm{kg}$ improved liver function and attenuated endothelial cell damage in Kunming mice model of Gynura segetum-induced hepatic sinusoidal obstruction syndrome (HSOS) [69]. Further, S. miltiorrhiza decreased the expression of TNF- $\alpha$, vascular cell adhesion molecule 1 (VCAM-1), intercellular adhesion molecule-1 (ICAM-1), and NF- $\mathrm{B}$ p65, thereby inhibiting HSOS in a dose-dependent manner. According to Gao et al., Danhong injection (DHI), a mixture extract of S. miltiorrhiza and Carthamus tinctorius (5:2), at a dose of $3 \mathrm{~g} / \mathrm{kg}$ (crude drugs weight/body weight) for $30 \mathrm{~min}$ showed anti-inflammatory, anti-oxidative, and anti-apoptotic effects in an lipopolysaccharide (LPS, $16 \mathrm{mg} / \mathrm{kg}$ )-induced mouse model of acute hepatic injury [70]. The intraperitoneal administration of DHI ameliorated the aberrant changes in biochemical markers, including alanine transaminase (ALT), aspartate transaminase (AST), and total bilirubin (TBil) levels in serum and malondialdehyde (MDA) and glutathione-S-transferase (GST) levels in liver homogenates. Further, DHI inhibited the expression of TNF- $\alpha$, IL-6, caspase-3, and Bax and the phosphorylation of the inhibitor of nuclear

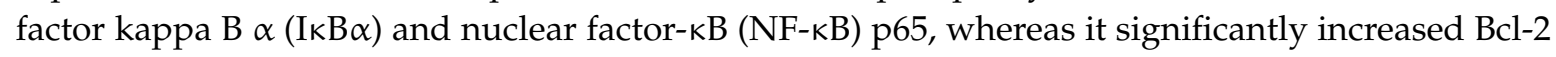
expression. Parajuli et al. examined the effect of PF2401-SF, a standardized and purified ethanol extract of $S$. miltiorrhiza, on gene and protein expression of liver fibrosis-related factors in mice with liver fibrosis induced by thioacetamide (TAA) [71]. Oral administration of PF2401-SF at doses of 1 or $2.5 \mathrm{mg} / \mathrm{kg}$ for 12 weeks resulted in improvement in serum levels of AST and ALT, reduction in fibrous tissue deposition as observed with H\&E staining, and down-regulation of COL I $(\alpha)$, TIMP-1, and $\alpha$-SMA expression. Given that $\alpha$-SMA is a vital marker for hepatic stellate cells (HSCs) activation, the anti-fibrotic effect of PF2401-SF was suggested to be attributed to the decreased HSC activation. PF2401-SF had hepatoprotective and anti-fibrotic effects on liver fibrosis. According to Peng et al., $90 \%$ ethanol extract of $S$. miltiorrhiza was reported to have an anti-fibrotic effect on carbon tetrachloride $\left(\mathrm{CCl}_{4}\right)$-induced liver fibrosis in mice possibly via the activation of hepatic natural killer cells [72]. Administration of $S$. miltiorrhiza extract at doses of 1.5 and $3.0 \mathrm{~g} / \mathrm{kg}$ for 4 weeks ameliorated $\mathrm{CCl}_{4}$-induced liver injury and fibrosis in mice, as assessed by H\&E and Sirius Red staining, serum ALT and AST levels, and Hyp contents. Besides, in vivo S. miltiorrhiza extract administration at a dose of $3 \mathrm{~g} / \mathrm{kg}$ up-regulated the frequency of NK cells and the expression of their active receptors, natural killer group 2D (NKG2D) and natural killer p46 (Nkp46). In vitro pre-incubation of NK cells with S. miltiorrhiza extract at a dose of $50 \mu \mathrm{g} / \mathrm{mL}$ for $16 \mathrm{~h}$ in the presence of interleukin-2 (IL-2) resulted in the increased expression of NKG2D and interferon gamma (IFN- $\gamma$ ), as well as the increased activation of primary NK cells. S. miltiorrhiza extract pretreatment for $16 \mathrm{~h}$ enhanced the inhibitory function of NK cells on the activation of hematopoietic stem cells (HSCs) (in this case, JS-1 cells) as assessed by the decreased level of $\alpha$-SMA and the increased level of RAE- $1 \varepsilon$, the NK cell stimulatory ligand on the surface of JS- 1 cells. Lee et al. showed that a standardized ethanol extract of $S$. miltiorrhiza could inhibit the development and progression of non-alcoholic steatohepatitis (NASH) [73]. In vivo, S. miltiorrhiza extract administration at doses of 0.5 or $1 \mathrm{mg} / \mathrm{kg}$ every other day for 4 or 6 weeks improved histopathological changes such as the inflammation and fibrosis of hepatocytes in a mouse model of NASH induced by a methionine-choline deficient (MCD) diet, as evaluated by H\&E and Sirius Red staining. In vivo S. miltiorrhiza extract administration for 4 weeks also down-regulated hepatic protein expression of TNF- $\alpha$ and COL I and mRNA expression of NASH-related specific genes such as TNF- $\alpha$, TGF- $\beta_{1}$, IL- $1 \beta$, 
C-reactive protein (CRP), $\alpha$-SMA, COL I, MMP-2, MMP-9. In vitro treatment with $S$. miltiorrhiza extract produced similar results in TGF- $\beta_{1}$-induced LX-2 human hepatic stellate cells. Besides, pretreatment with S. miltiorrhiza extract at doses of $0.1,1,10$, or $100 \mu \mathrm{g} / \mathrm{mL}$ for $30 \mathrm{~min}$ ameliorated intracellular ROS production in LX-2 cells later treated with hydrogen peroxide $\left(\mathrm{H}_{2} \mathrm{O}_{2}\right)$ for $15 \mathrm{~min}$, suggesting its antioxidant role. Lee et al. demonstrated the administration of $\mathrm{CG}^{\text {plus }}$, a standardized water extract of Artemisia iwayomogi, Amomum xanthioides, and S. miltiorrhiza, exerted a protective effect in a C57/BL6J mice model of NASH [74]. CG ${ }^{\text {plus }}$ administration at doses of 50, 100, and $200 \mathrm{mg} / \mathrm{kg}$ for 5 days down-regulated the protein and mRNA expression of pro-inflammatory cytokines (TNF- $\alpha$, IL-1 $\beta$, IL-6) and up-regulated the expression of anti-inflammatory cytokine IL-10. In addition, it increased the mRNA expression of lipolytic molecules (AMP-activated protein kinase [AMPK] and acyl-CoA dehydrogenase long chain [ACADL]) and the protein expression of p-AMPK, whereas it decreased the mRNA expression of lipogenic molecules including 3-hydroxy-3-methyl-glutaryl-coenzyme A reductase $[\mathrm{HMGCR}]$ and the protein expression of phosphorylated sterol regulatory element-binding protein 1 (SREBP-1). According to Feng et al., Jianpi Huoxue formula (JPHX) composed of Atractylodes macrocephal, S. miltiorrhiza, Radix Paeonia alba, Rhizoma alismatis, and Fructus Schisandrae chinensis had beneficial effects on nonalcoholic fatty liver disease (NAFLD) by regulating lipid accumulation, inflammation, fibrosis, and apoptosis [75]. In vivo administration of JPHX at doses of 0.6, 1.21, or $2.42 \mathrm{~g} / \mathrm{kg}$ once a day for 8 weeks ameliorated hepatic injury and inflammation, as shown by the decreased AST and ALT levels and TNF- $\alpha$ expression, and inhibited the accumulation of hepatic triglycerides (TG) and total cholesterol (TC) in MCD diet-fed rats. Further, it suppressed hepatic fibrosis, as indicated by the decreased expression levels of profibrotic genes such as MMP-9 and COL I. It was noteworthy that JPHX down-regulated hepatic apoptosis, as assessed by terminal deoxynucleotidyl transferase-mediated dUTP nick end labeling (TUNEL) assay, and a significant decrease in the expression of p-JNK was observed. Therapeutic targets of S. miltiorrhiza in liver diseases are presented in Figure 3. 
Table 3. Liver diseases and S. miltiorrhiza.

\begin{tabular}{|c|c|c|c|c|c|c|}
\hline Disease & Extract & Experimental Model & Dose; Duration & Efficacy & Mechanism & Reference \\
\hline $\begin{array}{c}\text { Alcoholic } \\
\text { liver } \\
\text { disease (ALD) }\end{array}$ & $\begin{array}{l}\text { Extractant unmentioned } \\
\text { (Danshen injection) }\end{array}$ & $\begin{array}{l}\text { (1) C57BL/6 mice } \\
\text { (2) HepG2 } \\
\text { (3) NCTC1469 }\end{array}$ & $\begin{array}{l}\text { (1) } 3 \mathrm{~g} / \mathrm{kg} ; 4 \text { weeks } \\
\text { (2) } 100,200 \mu \mathrm{g} / \mathrm{mL} ; 2 \mathrm{~h} \\
\text { (3) } 150 \mu \mathrm{g} / \mathrm{mL} ; 2 \mathrm{~h}\end{array}$ & $\begin{array}{c}\text { Hepatoprotective effect } \\
\text { against ALD }\end{array}$ & $\begin{array}{c}\uparrow \text { PPAR } \alpha, \text { CPT-1, CPT-2 } \\
\downarrow 4 \text {-HNE }\end{array}$ & [65] \\
\hline Alcoholic liver fibrosis (ALF) & $\begin{array}{c}\text { Pueraria lobata, Salvia } \\
\text { miltiorrhiza, Schisandra } \\
\text { chinensis, Silybum marianum } \\
\text { extract (8:5:4:3) }\end{array}$ & SD rats & $\begin{array}{c}0.333,0.667,1 \mathrm{~g} / \mathrm{kg} ; 30 \\
\text { days }\end{array}$ & Anti-fibrotic effect & $\begin{array}{l}\uparrow \text { MMP-13, Smad7 } \\
\downarrow \text { TIMP-1, TGF- } \beta_{1}, \\
\text { p-Smad2, p-Smad3 }\end{array}$ & [66] \\
\hline APAP-induced hepatotoxicity & Water & $\begin{array}{l}\text { (1) Primary SD rat } \\
\text { hepatocytes } \\
\text { (2) SD rat liver } \\
\text { microsomes }\end{array}$ & $\begin{array}{l}\text { (1) } 0.25,1 \mathrm{mg} / \mathrm{mL} ; 24 \mathrm{~h} \\
\text { (2) } 0.25,1 \mathrm{mg} / \mathrm{mL} ; 24 \mathrm{~h}\end{array}$ & $\begin{array}{l}\text { Antioxidant and } \\
\text { anti-hepatotoxic effects }\end{array}$ & $\begin{array}{c}\uparrow \text { GSH/GSSG ratio } \\
\downarrow \text { CYP2E1 }\end{array}$ & [68] \\
\hline $\begin{array}{l}\text { Hepatic sinusoidal } \\
\text { obstruction syndrome } \\
\text { (HSOS) }\end{array}$ & Extractant unmentioned & KM mice & $100,200 \mathrm{mg} / \mathrm{kg} ; \mathrm{N} / \mathrm{A}$ & $\begin{array}{l}\text { Hepatoprotective effect } \\
\text { on Gynura } \\
\text { segetum-induced HSOS }\end{array}$ & $\begin{array}{l}\downarrow \text { TNF- } \alpha, \text { VCAM-1, } \\
\text { ICAM-1, NF- } \kappa B \text { p65 }\end{array}$ & [69] \\
\hline LPS-induced liver injury & $\begin{array}{l}\text { Salvia miltiorrhiza, Carthamus } \\
\text { tinctorius extract }(5: 2)\end{array}$ & C57BL/6J mice & $3 \mathrm{~g} / \mathrm{kg} ; 30 \mathrm{~min}$ & $\begin{array}{l}\text { Anti-inflammatory, } \\
\text { anti-oxidative, and } \\
\text { anti-apoptotic effects }\end{array}$ & $\begin{array}{c}\uparrow \text { Bcl-2 } \\
\downarrow \text { TNF- } \alpha, \text { IL-6, p-NF-kB } \\
\text { p65, p-IкB } \alpha, \text { Bax }\end{array}$ & [70] \\
\hline Liver fibrosis & Ethanol & SD rats & $1,2.5 \mathrm{mg} / \mathrm{kg} ; 12$ weeks & $\begin{array}{c}\text { Anti-fibrotic effect against } \\
\text { TAA-induced liver } \\
\text { fibrosis }\end{array}$ & $\begin{array}{c}\downarrow \text { COL I }(\alpha), \text { TIMP- }-1, \\
\alpha \text {-SMA }\end{array}$ & [71] \\
\hline Liver fibrosis & $90 \%$ ethanol & $\begin{array}{l}\text { (1) C57BL/6 mice } \\
\text { (2) NK cells } \\
\text { (3) JS-1, NK cells } \\
(1: 50)\end{array}$ & $\begin{array}{c}\text { (1) } 1.5,3.0 \mathrm{~g} / \mathrm{kg} ; 4 \\
\text { weeks } \\
(2,3) 50 \mu \mathrm{g} / \mathrm{mL} ; 16 \mathrm{~h}\end{array}$ & $\begin{array}{l}\text { Anti-fibrotic effect against } \\
\mathrm{CCl}_{4} \text {-induced liver } \\
\text { fibrosis }\end{array}$ & $\begin{array}{c}(1,2) \uparrow \mathrm{NKG} 2 \mathrm{D}, \mathrm{NKp} 46, \\
\mathrm{IFN}-\gamma \\
(3) \uparrow \mathrm{RAE}-1 \varepsilon, \downarrow \alpha-\mathrm{SMA}\end{array}$ & [72] \\
\hline $\begin{array}{l}\text { Non-alcoholic steatohepatitis } \\
\text { (NASH) }\end{array}$ & $70 \%$ ethanol & $\begin{array}{l}\text { (1) C57BL/6j mice } \\
(2,3) \text { LX-2 }\end{array}$ & $\begin{array}{c}\text { (1) } 0.5,1 \mathrm{mg} / \mathrm{kg} ; 4,6 \\
\text { weeks } \\
\text { (2) } 0.1,0.5,1 \mu \mathrm{g} / \mathrm{mL} \text {; } \\
24 \mathrm{~h} \\
\text { (3) } 0.1,1,10,100 \\
\mu \mathrm{g} / \mathrm{mL} ; 30 \mathrm{~min}\end{array}$ & $\begin{array}{l}\text { Anti-inflammatory, } \\
\text { anti-fibrotic, and } \\
\text { antioxidant effects }\end{array}$ & $\begin{array}{c}\downarrow \text { TNF- } \alpha, \text { TGF- } \beta_{1}, \text { IL- } 1 \beta, \\
\alpha \text {-SMA, COL I, MMP- } 2, \\
\text { MMP-9, ROS }\end{array}$ & [73] \\
\hline
\end{tabular}


Table 3. Cont.

\begin{tabular}{|c|c|c|c|c|c|c|}
\hline Disease & Extract & Experimental Model & Dose; Duration & Efficacy & Mechanism & Reference \\
\hline $\begin{array}{l}\text { Non-alcoholic steatohepatitis } \\
\text { (NASH) }\end{array}$ & $\begin{array}{c}\text { Artemisia iwayomogi, } \\
\text { Amomum xanthioides, Salvia } \\
\text { miltiorrhizawater extract } \\
\text { (CGplus) }\end{array}$ & C57/BL6J mice & $\begin{array}{c}50,100,200 \mathrm{mg} / \mathrm{kg} ; 5 \\
\text { days }\end{array}$ & $\begin{array}{l}\text { Protection against the } \\
\text { development of NASH }\end{array}$ & $\begin{array}{c}\uparrow(\mathrm{p})-\mathrm{AMPK}, \mathrm{ACADL}, \\
\text { IL-10 } \\
\downarrow \text { TNF- } \alpha, \text { IL-1 } \beta, \text { IL-6, } \\
\text { HMGCR, p-SREBP-1 }\end{array}$ & [74] \\
\hline $\begin{array}{l}\text { Non-alcoholic fatty liver } \\
\text { disease (NAFLD) }\end{array}$ & $\begin{array}{c}\text { Atrctylodes macrocephaly, } \\
\text { Salvia miltiorrhiza, Radix } \\
\text { Paeonia Alba, Rhizoma } \\
\text { Alismatis, Fructus Schisandrae } \\
\text { Chinensis powdered extract } \\
\text { (JPHX formula) }\end{array}$ & Wistar rat & $\begin{array}{c}0.60,1.21,2.42 \mathrm{~g} / \mathrm{kg} ; 8 \\
\text { weeks }\end{array}$ & $\begin{array}{l}\text { Hepatoprotective effect } \\
\text { against NAFLD }\end{array}$ & $\begin{array}{c}\downarrow \text { TG, TC, TNF- } \alpha, \text { COL I, } \\
\text { MMP-9, p-JNK }\end{array}$ & [75] \\
\hline \multicolumn{7}{|c|}{ 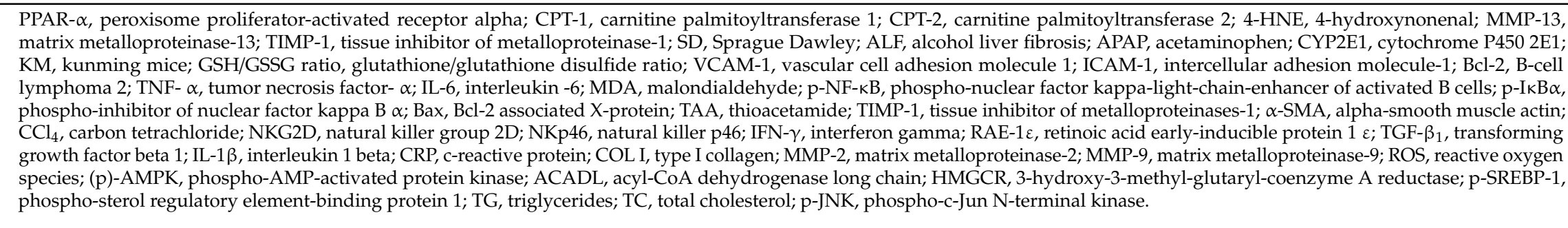 } \\
\hline
\end{tabular}




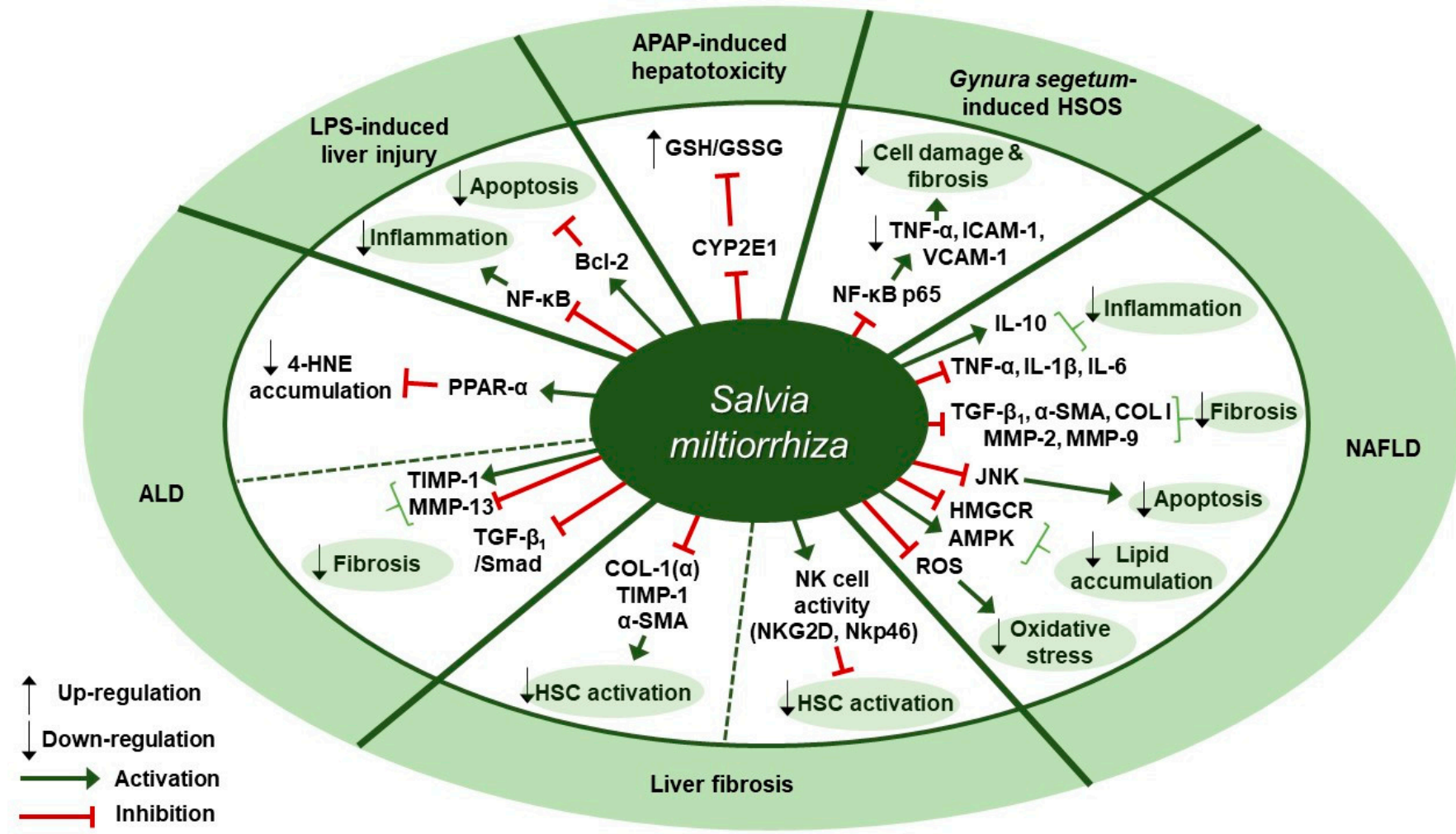

Figure 3. Therapeutic targets of S. miltiorrhiza in liver diseases. ALD, alcoholic liver disease; LPS, lipopolysaccharide; APAP, acetaminophen; HSOS, hepatic sinusoidal obstruction syndrome; NAFLD, non-alcoholic fatty liver disease; CYP2E1, cytochrome P450 2E; GSH/GSSG ratio, glutathione/glutathione disulfide ratio; NF-kB, nuclear factor kappa-light-chain-enhancer of activated B cells; TNF- $\alpha$, tumor necrosis factor- $\alpha$; ICAM-1, intercellular adhesion molecule-1; VCAM-1, vascular cell adhesion molecule 1; IL-10, interleukin 10; IL-1 $\beta$, interleukin 1 beta; IL-6, interleukin -6; TGF- $\beta 1$, transforming growth factor beta 1; $\alpha$-SMA, alpha-smooth muscle actin; COL I, type I collagen; MMP, matrix metalloproteinase; JNK, c-Jun N-terminal kinase; HMGCR, 3-hydroxy-3-methyl-glutaryl-coenzyme A reductase; AMPK, AMP-activated protein kinase; ROS, reactive oxygen species; NKG2D, natural killer group 2D; NKp46, natural killer p46; HSC, hepatic stellate cell; TIMP-1, tissue inhibitor of metalloproteinase-1; PPAR- $\alpha$, peroxisome proliferator-activated receptor alpha; 4-HNE, 4-hydroxynonenal; Bcl-2, B-cell lymphoma 2. 


\section{Nervous System Diseases}

As for nervous system diseases, neurodegenerative diseases such as Alzheimer's disease and cerebrovascular diseases such as ischemic stroke are two major categories of neurologic disorders and there has been a growing notion that the two are closely intertwined, with overlap in pathology and risk factors [76-79]. Alzheimer's disease is one of the most challenging diseases to cure and is the major cause of dementia [80]. Its pathophysiology has been associated not only with amyloid- $\beta$ (A $\beta)$ plaques, hyper-phosphorylated tau neurofibrillary tangles, and neuronal loss, all of which are classical pathological hallmarks of the disease [81]; but also with the cerebral blood flow shortfalls and blood-brain-barrier dysfunction, which are being given considerable attention as contributing factors to its pathogenesis [82]. There are currently five FDA-approved drugs for the treatment of Alzheimer's disease: rivastigmine, galantamine, donepezil, memantine, and memantine combined with donepezil [83]. Memantine, a non-competitive NMDA antagonist, proved to improve learning and memory by restoring homeostasis in the glutamatergic system [84]. The rest of them besides memantine are cholinesterase inhibitors (ChEIs) and are first-line, symptomatic treatments of the disease, with gastrointestinal side effects as the most common adverse reactions [85]. Ischemic stroke is by far the most common type of stroke, which ranks fifth among all causes of mortality. The stroke of this type is also referred to as brain ischemia or cerebral ischemia, and it accounts for $87 \%$ of all strokes [42]. When there is a reduction in cerebral blood flow due to a thrombus formation in the brain vasculature, ischemic stroke occurs [86]. Ischemic stroke is the major factor for vascular dementia, which accounts for around $10 \%$ of all dementia cases [87]. Post-stroke cognitive impairment is prevalent worldwide and the underlying mechanisms include vascular cognitive impairment owing to neuroanatomical lesions in such areas as hippocampus and white matter [88]. There are several other factors under investigation that make up the pathophysiology of ischemic stroke, such as post-stroke inflammation [89], apoptosis [90], and more specifically, protein kinase C activation [91].

\section{Nervous System Diseases and S. miltiorrhiza}

Several studies about neuroprotective effects of S. miltiorrhiza have been reported (Table 4). According to $\mathrm{Yu}$ et al., pre-treatment of SH-SY5Y cells with S. miltiorrhiza extract at doses of $0.01,0.1$, or $0.2 \mathrm{mg} / \mathrm{mL}$ for $2 \mathrm{~h}$ attenuated $\mathrm{A} \beta_{25-35}$-induced cell death through the inhibition of oxidative stress and mitochondria-dependent apoptotic pathway [92]. S. miltiorrhiza extract decreased the intracellular reactive oxygen species (ROS) levels, cleaved caspase-3 and cytosolic cytochrome c expression, and Bax/Bcl-2 ratio. Paudel et al. reported that S. miltiorrhiza extract significantly inhibited the expression of glycogen synthase kinase-3 $\beta$ (GSK-3 $\beta$ ) with $\mathrm{IC}_{50}$ values of $7.77 \pm 1.38$ [93]. According to Ozarowski et al., subchronic (28-fold) oral administration of $200 \mathrm{mg} / \mathrm{kg}$ S. miltiorrhiza extract for 28 days led to an improvement in long-term memory of rats as assessed by passive avoidance test, partially through inhibition of acetylcholinesterase (AChE) activity [94]. S. miltiorrhiza extract administration decreased AChE activity by $47 \%$ in the frontal cortex and by $55 \%$ in the hippocampus and decreased its relative mRNA expression in rat brain cortex homogenates by $41 \%(p<0.01)$ compared to the control group. Besides, it down-regulated the mRNA expression of butyrylcholinesterase (BuChE) by $48 \%(p<0.05)$ and $\beta$-secretase (BACE1) by $48 \%$ in the cortex, but there was no treatment-induced significant difference in the hippocampus of rat brain. Teng et al. reported that compound Danshen tablet (CDT) composed of S. miltiorrhiza, Panax notoginseng, and Borneol (450:141:8) had beneficial effects on cognitive function in $A \beta_{25-35}$-induced mice model when administered at doses of 0.405 or $0.81 \mathrm{~g} / \mathrm{kg}$ for 7 days [95]. CDT elevated choline acetyltransferase (CHAT) and receptor of activated protein kinase C1 (RACK1) levels and restored the balance between cytokines (interleukin-6 [IL-6] and tumor necrosis factor- $\alpha$ [TNF- $\alpha]$ ) and neurotrophins (brain-derived neurotrophic factor [BDNF]) in the hippocampus and cortex of brain. Similarly, Liu et al. demonstrated treatment with Danshen tablet of the same composition and proportion at a dose of $520 \mathrm{mg} / \mathrm{kg}$ for 14 days enhanced spatial learning and memory in $A \beta_{25-35}$ peptide-induced rat model by increasing the expression levels of insulin-degrading enzyme (IDE) and decreasing the expression levels of amyloid 
precursor protein (APP) and presenilin-1 (PS1) [96]. Kim et al. demonstrated the administration of S. miltiorrhiza extract at a dose of $50 \mathrm{mg} / \mathrm{kg}$ for 2 weeks in combination with $1 \times 10^{6}$ mesenchymal stem cells (MSC) resulted in synergetic therapeutic effects on the recovery of ischemic stroke in a rat middle cerebral artery occlusion model via enhancing the anti-apoptotic and survival ability of MSCs under hypoxic conditions [97]. Treatment with S. miltiorrhiza extract up-regulated the expression of Bcl-2, phospho-protein kinase B (p-Akt), and phospho-extracellular signal-regulated kinase (p-ERK) and down-regulated the expression of Bax and caspase-3. According to Wang et al., salvianolate lyophilized injection (SLI), which was obtained by $80 \%$ ethanol extraction of S. miltiorrhiza, protected against cerebral ischemic injury in type 1 diabetic rats subjected to intraluminal middle cerebral artery occlusion through down-regulation of inflammatory factors and up-regulation of nuclear factor erythroid 2-related factor 2 (Nrf2)/heme oxygenase-1 (HO-1) antioxidant pathway [98]. Administration of SLI at doses of 5.25, 10.5 , or $21 \mathrm{mg} / \mathrm{kg}$ for 15 days attenuated neural cell injury in the ischemic penumbra of cortex as assessed by H\&E staining. Further, it down-regulated receptor for advanced glycation endproducts (RAGE), matrix metalloproteinase-9 (MMP-9), cyclooxygenase-2 (COX-2), TNF- $\alpha$, and intercellular adhesion molecule-1 (ICAM-1) expression and up-regulated HO-1, NAD (P) H quinine oxidoreductase (HQO-1), and Nrf2 expression. Fei et al. demonstrated that supercritical $\mathrm{CO}_{2}$ and $95 \%$ ethanol extract of S. miltiorrhiza could alleviate permanent cerebral ischemic injury induced by permanent middle cerebral artery occlusion (pMCAO) in rats via activating phospholipase (PLC)/protein kinase C (PKC) signaling pathway [99]. Specifically, in vivo experiments were conducted at doses of $3.75,7.5$, or $15 \mathrm{mg} / \mathrm{kg}$ once daily for 3 days to assess the effect of $S$. miltiorrhiza extract on thrombosis formation and platelet aggregation, while in vitro experiments were conducted on platelets from rat plasma at doses of $0.44,4.4$, or $44 \mathrm{mg} / \mathrm{L}$ for $10 \mathrm{~min}$ to assess platelet aggregation, thromboxane $\mathrm{A}_{2}\left(\mathrm{TXA}_{2}\right)$ release, and the activation of platelet activating proteins (PLC $33, \mathrm{PKC}$ ). Treatment with S. miltiorrhiza extract at different doses inhibited thrombosis formation and platelet aggregation, inhibited TXA 2 release, and down-regulated p-PLC 33 and p-PKC expression. According to Zhang et al., the water extract of S. miltiorrhiza, Ligusticum chuanxiong, and Carthamus tinctorius, orally administered into mice with middle cerebral artery occlusion (MCAO), could help to prevent acute cerebral ischemic injury and recover cognitive impairment through inhibition of microenvironmental inflammation and activation of neurogenesis in the hippocampus [100]. Pretreatment with the mixture extract at a dose of $20 \mathrm{~g} / \mathrm{kg}$ for 5 days had a preventive effect in MCAO mouse model by reversing the up-regulation of Bax, interleukin-1 $\beta$ (IL-1 $\beta$ ), IL-6, and TNF- $\alpha$ expression and the down-regulation of Bcl-2 expression. Chronic treatment at a dose of $20 \mathrm{~g} / \mathrm{kg}$ for 28 days attenuated ischemia-induced spatial memory impairments, as evidenced by the decreased escape latency test in the Morris water maze test, and it greatly increased neurogenesis and BDNF expression. Cai et al. showed that an intraperitoneal injection of S. miltiorrhiza extract at a dose of $5 \mathrm{~mL} / \mathrm{kg} /$ day for 4 weeks could ameliorate the learning and memory decline of diabetic rats, as shown by the improved escape latency and platform-finding frequency in the Morris water maze test and the increased mitogen-activated protein kinase-1 (MKP-1) protein expression under the hyperglycemic condition [101]. According to Kim et al., the oral administration of S. miltiorrhiza extract could protect against the damage to the white matter and hippocampus in bilateral common carotid artery occlusion (BCCAo) rat model possibly via myeloid differentiation primary response 88 (MyD88)-dependent toll-like receptor 4 (TLR4) pathway [102]. S. miltiorrhiza extract administration at a dose of $200 \mathrm{mg} / \mathrm{kg} / \mathrm{day}$ for 22 days attenuated the BCCAo-induced increase in TNF- $\alpha$, IL-1 $\beta$, IL-6, TLR4, and MyD88 and the decrease in myelin basic protein (MBP). Park et al. demonstrated that the ethanol extract of $S$. miltiorrhiza alleviated ethanol-induced behavioral and synaptic deficits in mice via regulating N-methyl-d-aspartate (NMDA) receptor-dependent synaptic transmission [103]. S. miltiorrhiza (200 $\mathrm{mg} / \mathrm{kg})$, orally administered $30 \mathrm{~min}$ prior to ethanol treatment, protected against the impairment of object recognition memory. Twenty minutes of S. miltiorrhiza perfusion at doses of 10 or $100 \mu \mathrm{g} / \mathrm{mL}$ before ethanol perfusion substantially mitigated ethanol-induced long-term potentiation (LTP) and NMDA receptor-mediated field excitatory post-synaptic potential (fEPSP) deficits in the hippocampal slices. According to Zhang et al., 75\% ethanol extract of $S$. miltiorrhiza exerted a beneficial 
effect on the recovery of locomotor function after spinal cord injury (SCI) in rats [104]. S. miltiorrhiza extract administration at a dose of $12.5 \mathrm{~g} / \mathrm{kg}$ for 8 days improved motor function of SCI rats, as assessed by the Basso, Beattie, and Bresnahan locomotor scale, and ameliorated histopathological changes in the injured spinal cord, as observed with H\&E staining. Besides, it up-regulated the expression of neurofilament 200 (NF-H) (a mature neuron marker), BDNF, and cluster of differentiation molecule 11B (CD11b) (a microglia marker). These results were indicative of axonal regeneration, spinal cord repair, and microglial cells activation, respectively. Jia et al. reported that compound Danshen dripping pills (CDDP) composed of S. miltiorrhiza, Panax ginseng, and Borneol, alone or in combination with carbamazepine (CBZ), had protective and cognitive improving effects in a kainic acid-induced temporal lobe epilepsy (TLE) rat model [105]. The intragastric administration of CDDP at a dose of $85 \mathrm{mg} / \mathrm{kg}$ for 90 days alone or in combination with CBZ at a dose of $100 \mathrm{mg} / \mathrm{kg}$ attenuated cognitive impairment as assessed by the Morris water maze test. Further, it increased glial cell line-derived neurotrophic factor (GDNF) expression and the Bcl-2/Bax ratio in the hippocampal CA3 region, thereby minimizing the neuronal cell death. Therapeutic targets of $S$. miltiorrhiza in nervous system diseases are shown in Figure 4. 
Table 4. Nervous system diseases and S. miltiorrhiza.

\begin{tabular}{|c|c|c|c|c|c|c|}
\hline Disease & Extract & Experimental Model & Dose; Duration & Efficacy & Mechanism & Reference \\
\hline $\begin{array}{l}\text { Alzheimer's } \\
\text { disease (AD) }\end{array}$ & Water & SH-SY5Y cells & $\begin{array}{c}0.01,0.1,0.2 \mathrm{mg} / \mathrm{mL} ; \\
2 \mathrm{~h}\end{array}$ & $\begin{array}{c}\text { Neuroprotection against } \\
\mathrm{A} \beta_{25-35} \text {-induced } \\
\text { neurotoxicity }\end{array}$ & $\begin{array}{l}\downarrow \text { ROS, Bax/Bcl-2, } \\
\text { cytochrome c, caspase-3 }\end{array}$ & [92] \\
\hline $\begin{array}{l}\text { Alzheimer's } \\
\text { disease (AD) }\end{array}$ & Water & $\begin{array}{l}\text { Human recombinant } \\
\text { GSK-3 } \beta\end{array}$ & $\begin{array}{c}\mathrm{IC}_{50}: 7.77 \pm 1.38 \\
\mu \mathrm{g} / \mathrm{mL}\end{array}$ & Inhibition of AD & $\downarrow$ GSK-3 $\beta$ & [93] \\
\hline $\begin{array}{l}\text { Alzheimer's } \\
\text { disease (AD) }\end{array}$ & $50 \%$ ethanol & Wistar rats & $200 \mathrm{mg} / \mathrm{kg} ; 28$ days & $\begin{array}{c}\text { Improvement of } \\
\text { long-term memory of rats }\end{array}$ & $\downarrow$ AChE, BuChE, BACE1 & [94] \\
\hline $\begin{array}{l}\text { Alzheimer's } \\
\text { disease (AD) }\end{array}$ & $\begin{array}{l}\text { Salvia miltiorrhiza, } \\
\text { Panax Notoginseng, } \\
\text { Borneol extract } \\
(450: 141: 8)\end{array}$ & Kunming mice & $\begin{array}{l}0.405,0.81 \mathrm{~g} / \mathrm{kg} \\
7 \text { days }\end{array}$ & $\begin{array}{c}\text { Neuroprotective, } \\
\text { anti-inflammatory, } \\
\text { neurotrophic effects on } \\
\text { learning and memory in } \\
\mathrm{A} \beta_{25-35} \text {-induced mice }\end{array}$ & $\begin{array}{c}\uparrow \text { ChAT, BDNF, RACK1 } \\
\downarrow \text { IL-6, TNF- } \alpha\end{array}$ & [95] \\
\hline $\begin{array}{l}\text { Alzheimer's } \\
\text { disease (AD) }\end{array}$ & $\begin{array}{c}\text { Salvia miltiorrhiza, } \\
\text { Panax Notoginseng, } \\
\text { Borneol ethanol extract } \\
\quad(450: 141: 8)\end{array}$ & SD rats & $520 \mathrm{mg} / \mathrm{kg}$; 14 days & $\begin{array}{l}\text { Improvement of spatial } \\
\text { learning and memory in } \\
\mathrm{A} \beta_{25-35} \text {-induced rat } \\
\text { model of AD }\end{array}$ & $\begin{array}{c}\uparrow \text { IDE } \\
\downarrow \text { APP, PS1 }\end{array}$ & [96] \\
\hline $\begin{array}{l}\text { Brain Ischemic } \\
\text { Stroke }\end{array}$ & Water & $\begin{array}{l}\text { (1) MSCs } \\
\text { (2) SD rats }\end{array}$ & $\begin{array}{l}\text { (1) } 10 \mu \mathrm{g} / \mathrm{mL} \\
\text { (2) } 50 \mathrm{mg} / \mathrm{kg} \text {; } \\
2 \text { weeks }\end{array}$ & $\begin{array}{l}\text { Anti-apoptosis and } \\
\text { improvement of cell } \\
\text { survival }\end{array}$ & $\begin{array}{c}\uparrow \text { Bcl-2, p-Akt, p-ERK } \\
\downarrow \text { Bax, caspase-3 }\end{array}$ & [97] \\
\hline $\begin{array}{l}\text { Cerebral Ischemia } \\
\text { (Acute) }\end{array}$ & $80 \%$ ethanol & Wistar rats & $\begin{array}{c}5.25,10.5,21 \mathrm{mg} / \mathrm{kg} ; \\
15 \text { days }\end{array}$ & $\begin{array}{l}\text { Neuroprotective effect } \\
\text { against cerebral } \\
\text { ischemic injury }\end{array}$ & $\begin{array}{c}\uparrow \text { HO-1, HQO-1, Nrf-2 } \\
\downarrow \text { RAGE, MMP-9, COX-2, } \\
\text { TNF- } \alpha, \text { ICAM-1 }\end{array}$ & [98] \\
\hline
\end{tabular}


Table 4. Cont.

\begin{tabular}{|c|c|c|c|c|c|c|}
\hline Disease & Extract & Experimental Model & Dose; Duration & Efficacy & Mechanism & Reference \\
\hline $\begin{array}{l}\text { Cerebral Ischemia } \\
\text { (Permanent) }\end{array}$ & $\begin{array}{c}\text { Supercritical } \mathrm{CO}_{2} \text { and } \\
95 \% \text { ethanol }\end{array}$ & SD rats & $\begin{array}{c}(1) 15,7.5,3.75 \\
\mathrm{mg} / \mathrm{kg} / \mathrm{day} ; 3 \text { days } \\
(2) 0.44,4.4 \\
44 \mathrm{mg} / \mathrm{L} ; 10 \mathrm{~min}\end{array}$ & $\begin{array}{l}\text { Attenuation of cerebral } \\
\text { ischemic injury through } \\
\text { inhibitory effects on } \\
\text { thrombosis formation } \\
\text { and platelet aggregation } \\
\text { in rats }\end{array}$ & $\downarrow \mathrm{TXA}_{2}, \mathrm{p}-\mathrm{PLC} \beta 3, \mathrm{p}-\mathrm{PKC}$ & [99] \\
\hline Cerebral Ischemia & $\begin{array}{c}\text { Salvia miltiorrhiza, } \\
\text { Ligusticum chuanxiong, } \\
\text { Carthamus tinctorius } \\
\text { water extract-Ratio } \\
\text { unmentioned }\end{array}$ & Kunming mice & $\begin{array}{l}\text { (1) } 20 \mathrm{~g} / \mathrm{kg} ; 5 \text { days } \\
\text { (2) } 20 \mathrm{~g} / \mathrm{kg} ; 28 \text { days }\end{array}$ & $\begin{array}{l}\text { Recovery of cognitive } \\
\text { impairment and } \\
\text { Neuroprotection against } \\
\text { cerebral ischemic injury }\end{array}$ & $\begin{array}{c}\uparrow \text { Bcl-2, BDNF } \\
\downarrow \text { IL- } 1 \beta, \text { IL-6, TNF- } \alpha \text {, Bax }\end{array}$ & [100] \\
\hline Dementia & $\begin{array}{c}\text { Extractant } \\
\text { unmentioned }\end{array}$ & SD rats & $\begin{array}{l}5 \mathrm{~mL} / \mathrm{kg} / \text { day; } \\
4 \text { weeks }\end{array}$ & $\begin{array}{c}\text { Improvement of learning } \\
\text { and memory abilities in } \\
\text { streptozotocin-induced } \\
\text { diabetic rats }\end{array}$ & $\uparrow \mathrm{MKP}-1$ & [101] \\
\hline $\begin{array}{l}\text { Dementia, } \\
\text { Vascular }\end{array}$ & Water & Wister rats & $\begin{array}{l}200 \mathrm{mg} / \mathrm{kg} / \text { day; } \\
22 \text { days }\end{array}$ & $\begin{array}{l}\text { Protection against } \\
\text { damage to the white } \\
\text { matter and hippocampus } \\
\text { after bilateral common } \\
\text { carotid artery occlusion }\end{array}$ & $\begin{array}{c}\uparrow \mathrm{MBP} \\
\downarrow \mathrm{TNF}-\alpha, \mathrm{IL}-1 \beta, \mathrm{IL}-6, \\
\text { TLR4, MyD88 }\end{array}$ & [102] \\
\hline $\begin{array}{c}\text { Ethanol-induced } \\
\text { Amnesia }\end{array}$ & $70 \%$ ethanol & CD-1 mice & $\begin{array}{l}\text { (1) } 200 \mathrm{mg} / \mathrm{kg} \text {; } \\
30 \mathrm{~min} \\
\text { (2) } 10,100 \mu \mathrm{g} / \mathrm{mL} \\
20 \mathrm{~min}\end{array}$ & $\begin{array}{c}\text { Blockage of } \\
\text { ethanol-induced synaptic } \\
\text { dysfunction }\end{array}$ & $\begin{array}{c}\uparrow \text { LTP, } \\
\text { NMDAR-dependent } \\
\text { fEPSP }\end{array}$ & [103] \\
\hline
\end{tabular}


Table 4. Cont.

\begin{tabular}{|c|c|c|c|c|c|c|}
\hline Disease & Extract & Experimental Model & Dose; Duration & Efficacy & Mechanism & Reference \\
\hline $\begin{array}{l}\text { Spinal cord injury } \\
\text { (SCI) }\end{array}$ & $75 \%$ ethanol & SD rats & $12.5 \mathrm{~g} / \mathrm{kg} ; 8$ days & $\begin{array}{l}\text { Beneficial effects on the } \\
\text { recovery of locomotor } \\
\text { function after SCI }\end{array}$ & $\uparrow \mathrm{NF}-\mathrm{H}, \mathrm{BDNF}, \mathrm{CD} 11 \mathrm{~b}$ & [104] \\
\hline $\begin{array}{l}\text { Temporal Lobe } \\
\text { Epilepsy (TLE) }\end{array}$ & $\begin{array}{c}\text { Extractant } \\
\text { unmentioned } \\
\text { Salvia miltiorrhiza } \\
\text { Bunge, Panax } \\
\text { notoginseng, } \\
\text { Borneol-Ratio } \\
\text { unmentioned }\end{array}$ & SD rats & $85 \mathrm{mg} / \mathrm{kg}$; 90 days & $\begin{array}{l}\text { Neuroprotection on a } \\
\text { kainic acid-induced TLE } \\
\text { and cognitive } \\
\text { impairment in rats }\end{array}$ & $\uparrow$ GDNF, Bcl-2/Bax & [105] \\
\hline
\end{tabular}

ROS, reactive oxygen species; Bax, Bcl-2 associated X protein; Bcl-2, B-cell lymphoma 2; GSK-3 $\beta$, glycogen synthase kinase-3 $\beta$; AchE, acetylcholinesterase; BuChE, butyrylcholinesterase; BACE1, $\beta$-secretase; ChAT, choline acetyltransferase; BDNF, brain derived neurotrophic factor; RACK 1, receptor of activated protein kinase C1; IL-6, interleukin-6; TNF- $\alpha$, tumor necrosis factor- $\alpha$; IDE, insulin-degrading enzyme; APP, amyloid precursor protein; PS1, presenilin-1; MSCs, mesenchymal stem cells; p-Akt, phospho-Akt (protein kinase B); p-ERK, phospho-extracellular signal-regulated kinase; HO-1, heme oxygenase-1; HQO-1, NAD(P)H quinine oxidoreductase; Nrf2, nuclear factor erythroid 2-related factor 2; RAGE, receptor for advanced glycation endproducts; MMP-9, matrix metalloproteinase-9; COX-2, cyclooxygenase-2; ICAM- 1, intercellular adhesion molecule-1; TXA2, thromboxane A2; pPLC $\beta 3$, phospho-phospholipase C $\beta 3$; p-PKC, phospho-protein kinase C; IL-1 $\beta$, interleukin-1 $\beta$; MKP-1, mitogen-activated protein kinase-1; MBP, myelin basic protein; TLR4, toll-like receptor 4; MyD88, myeloid differentiation primary response 88; LTP, long-term potentiation; NMDAR, N-methyl-d-aspartate receptor; fEPSP, field excitatory postsynaptic potential; NF-H, neurofilament 200; CD11b, cluster of differentiation molecule 11B; GDNF, glial cell line-derived neurotrophic factor. 


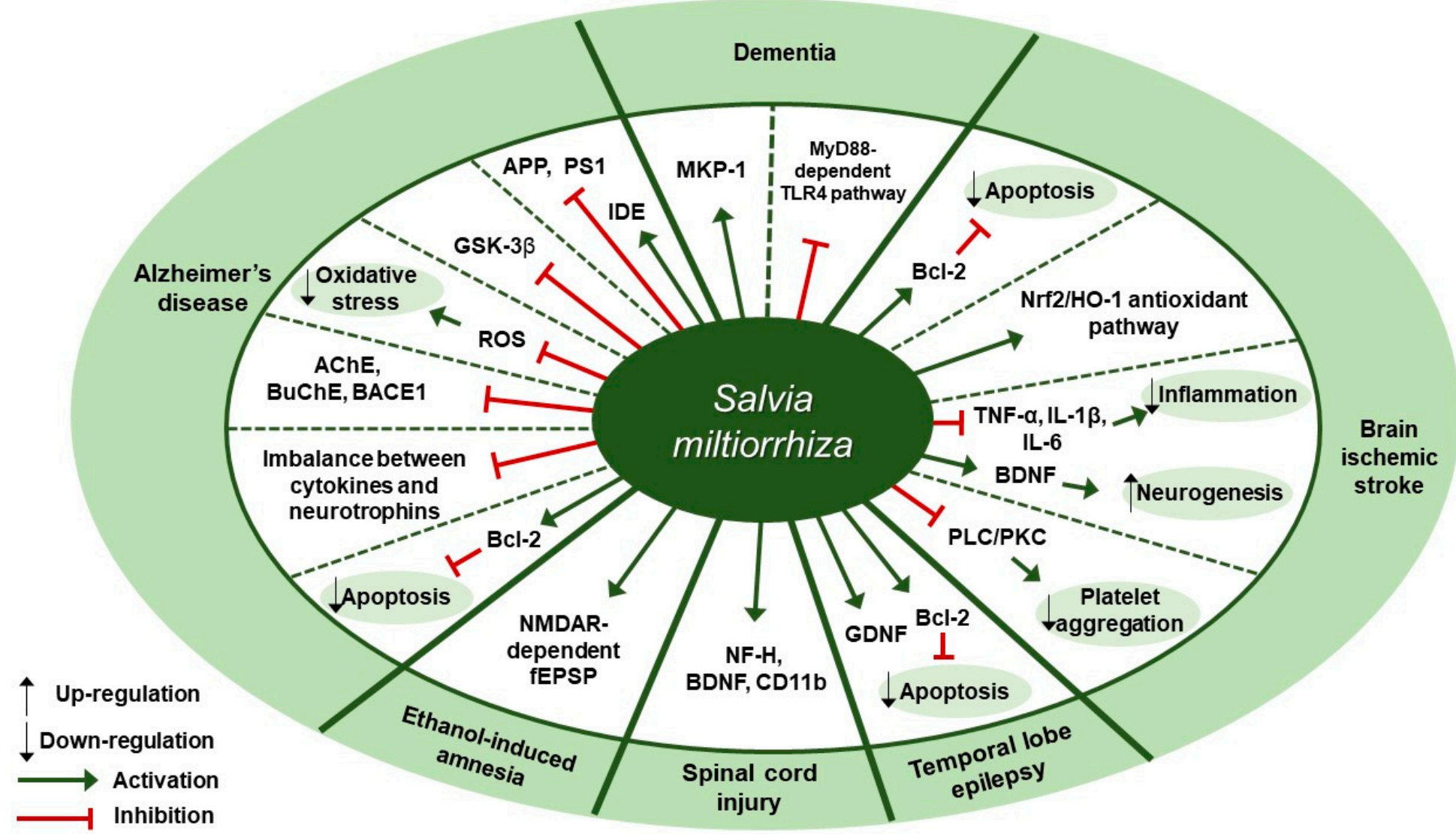

Figure 4. Therapeutic targets of $S$. miltiorrhiza in nervous system diseases. MKP-1, mitogen-activated protein kinase-1; MyD88, myeloid differentiation primary response 88; TLR4, toll-like receptor 4; Bcl-2, B-cell lymphoma 2; Nrf2, nuclear factor erythroid 2-related factor 2; HO-1, heme oxygenase-1; TNF- $\alpha$, tumor necrosis factor- $\alpha$; IL-1 $\beta$, interleukin-1 $\beta$; IL-6, interleukin-6; BDNF, brain-derived neurotrophic factor; PLC, phospholipase; PKC, protein kinase C; GDNF, glial cell-derived neurotrophic factor; NF-H, neurofilament 200; CD11b, cluster of differentiation molecule 11B; NMDAR, N-methyl-d-aspartate receptor; fEPSP, field excitatory postsynaptic potential; AchE, acetylcholinesterase; BuChE, butyrylcholinesterase; BACE1, $\beta$-secretase; ROS, reactive oxygen species; GSK-3 $\beta$, glycogen synthase kinase-3 $\beta$; APP, amyloid precursor protein; PS1, presenilin-1; IDE, insulin-degrading enzyme. 


\section{Discussion}

Salvia miltiorrhiza Bunge (S. miltiorrhiza), also known as dansam in Korean and danshen in Chinese, is a medicinal herb which belongs to genus Salvia of Lamiaceae family [2]. In Korea, it is known to be effective in removing blood stasis and enriching the blood according to the original text of Donguibogam (a classic written in the 17th century) [106]. It has been widely used for the treatment of various diseases, but there are only a few review articles addressing its multi-functional therapeutic potentials. Yan et al. reviewed its traditional medicinal uses and pharmacological properties based on articles reporting on the beneficial effects of compounds isolated from S. miltiorrhiza [107]. We, however, aimed to gather data on the efficacy of the whole herb extract of S. miltiorrhiza to obtain insights into how $S$. miltiorrhiza extract as a whole exerted its therapeutic effects in various diseases.

\subsection{S. miltiorrhiza Exhibits Anti-cancer Activity by Inducing Apoptosis in Cancer Cells}

In terms of cancer therapeutics, one major strategy is to induce apoptosis in cancer cells by triggering the key components of cell death signaling pathway such as Bcl-2 family of proteins and the caspases [108], or modulating the MAPK families [109]. Indeed, in most of the studies mentioned earlier in our review, induction of apoptosis in cancer cells was the major goal of each study and they mostly explored the detailed mechanisms by which $S$. miltiorrhiza extract exerted its apoptotic effects. In doing so, different doses of $S$. miltiorrhiza extract alone or mixed with other herb extracts were tested as a therapeutic agent in cancer cell lines or mouse xenograft models. Among them, some studies offered conflicting results regarding the mechanism by which $S$. miltiorrhiza extract induced apoptosis. For example, $95 \%$ ethanol extract of $S$. miltiorrhiza at doses between $10-50 \mu \mathrm{g} / \mathrm{mL}$ for 48 or $72 \mathrm{~h}$ induced apoptosis in OSCC cell lines, by down-regulating the expression of XIAP and survivin, two members of the inhibitor of apoptosis protein (IAP) family; however, treatment with S. miltiorrhiza extract did not change the levels of antiapoptotic proteins Bcl-2 and Bcl-xL and the proapoptotic proteins Bax and Bad, as well as apoptosis-related mitochondrial membrane potential [36]. In contrast, treatment with methanol extract of S. miltiorrhiza at doses between 10-40 $\mu \mathrm{g} / \mathrm{mL}$ for $24 \mathrm{~h}$ decreased the expression of Bcl-2 and Bcl-xl and increased the expression of Bax in Glc-82 cells; in addition, treatment with 20 and $40 \mu \mathrm{g} / \mathrm{mL}$ of $S$. miltiorrhiza extract increased the levels of cleaved caspase-9, caspase-3, and PARP1, suggesting the possibility of the involvement of the mitochondrial apoptotic pathway in S. miltiorrhiza extract-mediated cytotoxicity [34]. Wu et al.'s study supported this finding in that the treatment with S. miltiorrhiza extract induced apoptosis in CCRF-CEM cells through the intrinsic apoptotic signaling pathway, as evidenced by the increased expression of cleaved caspase-9, -7, -3, and PARP [40]. Lee et al. reported that the treatment with $S$. miltiorrhiza extract activated caspase-9, caspase-3, and PARP and did not impact the activity of caspase- 8 , but they concluded that the $S$. miltiorrhiza extract induced apoptosis exclusively through the extrinsic apoptotic signaling pathway [38], which seems to be a mistake since caspase-9 is considered as an upstream initiator required for the mitochondrial apoptotic pathway, or intrinsic apoptotic pathway, while caspase- 8 as an initiator caspase that mediates the extrinsic apoptotic pathway [110]. On the other hand, S. miltiorrhiza extract has been shown to modulate the MAPK families, which consist of multiple kinases altered in cancers and thereby have been considered a promising target [109]. According to Kim et al., treatment with S. miltiorrhiza extract at a dose of $50 \mu \mathrm{g} / \mathrm{mL}$ for $24 \mathrm{~h}$ specifically inhibited the MAPK/AP-1 signaling pathway in TPA-induced breast cancer cells and did not influence the phosphorylation of inhibitory $\kappa$ B kinase (IKK) $\alpha / \beta$ and IкB $\alpha$ subunit, degradation of I $\kappa \mathrm{B} \alpha$, or nuclear translocation of NF-kB p65 [30]. However, in Wu et al.'s study, treatment with $S$. miltiorrhiza extract at a dose of $20 \mu \mathrm{g} / \mathrm{mL}$ for $24 \mathrm{~h}$ inhibited the nuclear translocation of NF-KB p65 in CCRF-CEM cells, while down-regulation of ERK and JNK was observed in both studies [40]. These conflicting results warrant further research into the precise mechanism implicated in the anti-apoptotic effect of $S$. miltiorrhiza. 


\subsection{S. miltiorrhiza Exerts Anti-inflammatory and Anti-fibrotic Effects in Modulating Cardiovascular Diseases}

One major component of cardiovascular diseases (CVD) is the ischemic heart disease (IHD) [43], which encompasses a broad spectrum of clinical conditions including angina pectoris, unstable angina, and myocardial infarction (MI), all of which are characterized by myocardial ischemia [111]. A possible treatment approach to IHD is anti-inflammation in coronary artery [112], as illustrated by studies on IL-1 $\beta$ as a therapeutic target for the treatment of atherosclerotic vascular disease [113,114]. In this perspective, $S$. miltiorrhiza extract has recently been addressed in several studies as a potential anti-inflammatory agent in a mouse model of MI induced by LAD ligation; specifically, administration of $S$. miltiorrhiza extract reduced MI-induced inflammation, as evidenced by the decreased expression of proinflammatory cytokines such as IL-1 $\beta$, TNF, and IL-6 and the increased expression of anti-inflammatory cytokines IL-10 in Yang et al.'s study [52] and the decreased expression of iNOS and MPO in Wang et al.'s study [51]. Cardiac fibrosis is a common histopathological phenomenon in IHD and is characterized by the increased accumulation of extracellular matrix (ECM) that impairs cardiac function [115]. It has been suggested targeting fibrosis would be a promising therapeutic option for the treatment of chronic heart failure or other CVDs [116]. Most of the studies which were included in our review tested whether S. miltiorrhiza extract could inhibit cardiac fibrosis and ventricular remodeling. Various measures to assess cardiac fibrosis were used, such as immunohistochemistry and Masson's trichrome staining. For example, S. miltiorrhiza extract administration dose-dependently decreased the expression of COL I and COL III as assessed by immunohistochemistry and reduced areas of fibrotic heart tissue as observed with Masson's stain [49]. Two studies further examined the effect of $S$. miltiorrhiza extract on the expression levels of the profibrotic cytokine TGF- $\beta$, which is a major mediator implicated in fibrotic remodeling of the heart and is thought to drive fibroblast-myofibroblast differentiation [117]; in both studies, down-regulation of TGF- $\beta$ expression was observed, but different mechanisms were proposed regarding the anti-fibrotic effects of S. miltiorrhiza extract $[49,55]$.

\subsection{S. miltiorrhiza Exerts Several Effects in Modulating Liver Diseases}

To date, there is no proven effective treatment option for alcoholic liver disease (ALD) and non-alcoholic fatty liver disease (NAFLD), both of which are chronic liver diseases with a shared pathological spectrum ranging from simple steatosis to hepatitis to cirrhosis to hepatocellular carcinoma [64]. Natural compounds from plants have been suggested as an alternative to treat liver pathology and their hepatoprotective effects have been extensively investigated in terms of pharmacological properties including antioxidant, anti-inflammatory, anti-fibrotic, anti-apoptotic, and hepatoprotective activities [118]. Since oxidative stress plays a vital role in the pathogenesis of many liver diseases including ALD and NAFLD [119], the application of natural antioxidants could be a rational strategy for the treatment of liver diseases [120]. According to recent studies mentioned earlier in our review, S. miltiorrhiza could be a natural resource of antioxidants, as illustrated by Zhou et al.'s study [68] where S. miltiorrhiza extract attenuated the loss of total glutathione (GSH) by inhibiting CYP2E1 and preserved redox status expressed as GSH/GSSG level in rat hepatocytes. Lee et al. also demonstrated the antioxidant role of $S$. miltiorrhiza extract as indicated by the decreased intracellular ROS generation in LX-2 cells after treatment with $S$. miltiorrhiza extract at doses of $0.1,1,10$, or $100 \mu \mathrm{g} / \mathrm{mL}$ for $30 \mathrm{~min}$ [73]. On the other hand, several studies pointed out other therapeutic properties of S. miltiorrhiza extract, including anti-inflammatory and anti-fibrotic activities. For example, the anti-fibrotic effect of S. miltiorrhiza extract in a mouse model of thioacetamide-induced liver fibrosis was demonstrated in Parajuli et al.'s study, where S. miltiorrhiza extract administration at doses of 1 or $2.5 \mathrm{mg} / \mathrm{kg}$ for 12 weeks reduced fibrous tissue deposition and down-regulated the expression of central markers of fibrosis including COL I, TIMP-1, and $\alpha$-SMA [71]. While reduced activation of hepatic stellate cells (HSC) was proposed as a possible mechanism for the anti-fibrotic activity of $S$. miltiorrhiza extract in Parajuli et al.'s study, Peng et al. suggested that the administration of $S$. miltiorrhiza extract at doses of 1.5 or $3 \mathrm{~g} / \mathrm{kg}$ for 4 weeks attenuated $\mathrm{CCL}_{4}$-induced liver injury and fibrosis in mice through the activation of hepatic 
natural killer cells, which also contributed to HSC deactivation [72]. On the other hand, a few studies reported on the hepatoprotective effects of S. miltiorrhiza extract via modulating the activity of the NF- $\mathrm{kB}$ family of transcription factors, which have been implicated in liver injury with regard to its role in liver homeostasis and the regulation of inflammation, fibrosis, and carcinogenesis [121]. For instance, S. miltiorrhiza at doses of 100 or $200 \mathrm{mg} / \mathrm{kg}$ ameliorated endothelial cell damage in a rat model of Gynura segetum-induced hepatic sinusoidal obstruction syndrome (HSOS) when it down-regulated NF- $\mathrm{kB}$ p65, one of five components that form the NF- $\mathrm{kB}$ [69]. Inhibition of NF- $\mathrm{kB}$ by S. miltiorrhiza extract was associated with the decreased expression of proinflammatory cytokine, such as TNF- $\alpha$, and adhesion molecules, such as VCAM-1 and ICAM-1. NF-kB has long been considered to play both proinflammatory and antiapoptotic roles, but its functions are context-dependent and therefore require cautious interpretation [122]. Specifically, activating NF- $\mathrm{BB}$ in non-parenchymal cells such as stellate cells, Kupffer cells, and sinusoidal endothelial cells, in general, increase inflammation and fibrosis, while suppressing NF-kB activation in parenchymal cells lead to hepatocarcinogenesis [121]. In light of the complexity of the NF- $\mathrm{kB}$ system and its cell-type specific functions, further research to elucidate its association with the hepatoprotective effect of $S$. miltiorrhiza extract might be needed.

\subsection{S. miltiorrhiza Acts on Multiple Targets and Exhibits a Neuroprotective Effect on Several Nervous System Diseases}

Regarding nervous system diseases, there has been ongoing research into how S. miltiorrhiza extract can exert neuroprotective effects against multiple diseases including Alzheimer's disease (AD), ischemic stroke, and other neurological diseases. Since the advent of cholinesterase inhibitors (ChEIs) and $N$-methyl-d-aspartate (NMDA) receptor antagonist, the two drug classes currently available for $\mathrm{AD}$ treatment, extensive research has been conducted to find out novel therapeutic targets to treat $A D$, including butyrylcholinesterase (BuChE), $\beta$-secretase (BACE1), tau protein and related enzymes (e.g., GSK-3 $\beta$ ), and oxidative stress [123]. In keeping with these trends, several recent studies included in our review investigated different mechanisms regarding the neuroprotective effect of $S$. miltiorrhiza extract in $A \beta_{25-35}$-induced mouse or cell model of AD. For instance, Yu et al. demonstrated that treatment with S. miltiorrhiza extract at doses of $0.01,0.1,0.2 \mathrm{mg} / \mathrm{mL}$ for $2 \mathrm{~h}$ inhibited ROS generation in SH-SY5Y cells [92]. In addition, Paudel et al. reported on the inhibitory effect of S. miltiorrhiza extract on GSK-3 3 [93], while Ozarowski et al. examined the inhibitory effect of S. miltiorrhiza extract administration at a dose of $200 \mathrm{mg} / \mathrm{kg}$ for 28 days on AChE as well as BuChE and BACE1 in the rat brain cortex [94]. These multi-functional properties of $S$. miltiorrhiza extract suggest that it could act on multiple targets for the treatment of cognitive impairment and neurodegeneration. On the other hand, several other studies included in our review addressed the beneficial effect of $S$. miltiorrhiza extract on brain ischemic stroke, highlighting the antiplatelet [99], anti-inflammatory $[98,100]$, and anti-apoptotic activities [97] of S. miltiorrhiza extract. Specifically, Fei et al. reported on the anti-platelet activity of S. miltiorrhiza extract in a mouse model of cerebral ischemic injury and suggested the involvement of PLC and PKC in the antiplatelet effect of S. miltiorrhiza [99]. According to Wang et al., the neuroprotective effect of $S$. miltiorrhiza was attributed to its anti-inflammatory properties, as evidenced by the reduction of the expression of RAGE, MMP-9, and other inflammatory factors (COX, TNF- $\alpha$, ICAM-1), as well as its possible antioxidant activity evidenced by the activation of $\mathrm{Nrf2} / \mathrm{HO}-1$ signaling pathway [98]. Interestingly, Zhang et al. delved into the mechanism by which S. miltiorrhiza exerted a neuroprotective effect in a mouse model of spinal cord injury (SCI) [104]. S. miltiorrhiza extract administration at a dose of $12.5 \mathrm{~g} / \mathrm{kg}$ for 8 days improved locomotor function and histopathological changes in mice and up-regulated NF-H, BDNF, CD11b protein expression. They further explored its possible mechanism using metabolomics, identifying 51 SCI-specific metabolites and suggesting 6 metabolic pathways where the altered metabolites were significantly impacted by S. miltiorrhiza extract, including vitamin B6 metabolism, pentose and glucuronate interconversions, lysine degradation starch and sucrose metabolism, arachidonic acid metabolism, and steroid hormone biosynthesis. This kind of 
state-of-the-art approach to unravel the therapeutic mechanism of S. miltiorrhiza could contribute to the deeper understanding of its therapeutic potentials.

\subsection{Limitaions and Strong Points of This Study}

Due to the time constraints on our review, we used PubMed as the only source of documents, set a 5 -year time limit to our search for literature, excluded articles that were written in a language other than English, and focused our review on studies on specific disease groups that have been relatively well recognized and understood. In addition, heterogeneity between experiments may have influenced the interpretation of the results. Despite these limitations, our review was able to provide an overview of the efficacy of S. miltiorrhiza extract in various kinds of diseases so that the reader can obtain a broad picture of its multifaceted therapeutic benefits. In addition, we reviewed S. miltiorrhiza extract in multiple dosage forms, offering insights into how S. miltiorrhiza extract can deliver its therapeutic effects in various forms. This review can be regarded as a guide to further investigation rather than a conclusive analysis.

\section{Conclusions}

This review summarized recent experimental findings on the therapeutic effects of $S$. miltiorrhiza on cancers, cardiovascular, liver, and nervous system diseases. S. miltiorrhiza extract has been demonstrated to exert anti-inflammatory, anti-fibrotic, antioxidative, anti-apoptotic or pro-apoptotic, and neuroprotective effects in cell or animal model of such diseases. Despite current efforts to unravel the mechanism implicated in the multiple therapeutic effects of S. miltiorrhiza, it remains a major challenge to elucidate its multi-faceted therapeutic potentials.

Author Contributions: Conceptualization, B.K.; methodology, I.J.; investigation, I.J., H.K., S.M. and H.L.; writing-original draft preparation, I.J., H.K., S.M. and H.L.; writing-review and editing, I.J., B.K.; visualization, H.K., S.M. and H.L.; supervision, B.K.; project administration, B.K.; funding acquisition, B.K. All authors have read and agreed to the published version of the manuscript.

Funding: This work was supported by the National Research Foundation of Korea (NRF) grant funded by the Korea government (MSIT) (No. 2020R1A5A201941311) and Basic Science Research Program through the National Research Foundation of Korea (NRF) funded by the Ministry of Education (NRF-2020R1I1A2066868).

Conflicts of Interest: The authors declare no conflict of interest. The funders had no role in the design of the study; in the collection, analyses, or interpretation of data; in the writing of the manuscript, or in the decision to publish the results.

\section{Glossary}

$\begin{array}{ll}\text { 4-HNE } & \text { 4-hydroxynonenal } \\ 8 & \text { 9-DHET } \\ 8 & \text { 9-dihydroxyeicosatrienoic acids } \\ 8 & \text { 9-EET } \\ 8 & \text { 9-epoxyeicosatrienoic acid } \\ \text { ACADL } & \text { acyl-CoA dehydrogenase long chain } \\ \text { AchE } & \text { acetylcholinesterase } \\ \text { Acta2 } & \text { actin alpha 2 } \\ \text { Akt } & \text { protein kinase B } \\ \text { ALF } & \text { alcohol liver fibrosis } \\ \text { AMPK } & \text { AMP-activated protein kinase } \\ \text { AP-1 } & \text { activator protein-1 } \\ \text { APAP } & \text { acetaminophen } \\ \text { Apo } & \text { apolipoprotein } \\ \text { APP } & \text { amyloid precursor protein } \\ \text { ATF4 } & \text { activating transcription factor } 4\end{array}$




\begin{tabular}{|c|c|}
\hline BACE1 & $\beta$-secretase \\
\hline Bax & Bcl-2 associated $X$-protein \\
\hline Bad & Bcl-2 associated agonist of cell death \\
\hline $\mathrm{Bcl}-2$ & B-cell lymphoma 2 \\
\hline Bcl-xl & B-cell lymphoma-extra large \\
\hline $\mathrm{BDNF}$ & brain derived neurotrophic factor \\
\hline BNP & brain natriuretic peptide \\
\hline BuChE & butyrylcholinesterase \\
\hline c-caspase-3 & cleaved caspase- 3 \\
\hline c-PARP & cleaved poly ADP-ribose polymerase \\
\hline $\mathrm{CCl} 4$ & carbon tetrachloride \\
\hline CD11b & cluster of differentiation molecule 11B \\
\hline CDK & cyclin-dependent kinase \\
\hline ChAT & choline acetyltransferase \\
\hline $\mathrm{CHOP}$ & $\begin{array}{l}\text { CCAAT-enhancer-binding protein homologous } \\
\text { protein }\end{array}$ \\
\hline COL I & type I collagen \\
\hline COL III & type III collagen \\
\hline Colla1 & collagen type I alpha 1 \\
\hline Col3a1 & collagen type 3 alpha 1 \\
\hline COX-2 & cyclooxygenase-2 \\
\hline CPTI & carnitine palmitoyltransferase I \\
\hline CRP & c-reactive protein \\
\hline CTN & compounds of tanshinone \\
\hline $\mathrm{C} \times 43$ & connexin 43 \\
\hline CYP2E1 & cytochrome P450 2E1 \\
\hline DBil & direct bilirubin \\
\hline eIF2 & eukaryotic initiation factor 2 \\
\hline eNOS & endothelial nitric oxide synthase. \\
\hline ERK & extracellular-signal-regulated-kinase \\
\hline ERK & extracellular signal-regulated kinase \\
\hline FATP & fatty acids transport protein \\
\hline fEPSP & field excitatory postsynaptic potential \\
\hline GDNF & glial cell line-derived neurotrophic factor \\
\hline GGT & gamma-glutamyl transpeptidase \\
\hline GSH/GSSG ratio & glutathione/glutathione disulfide ratio \\
\hline GSK-3 $\beta$ & glycogen synthase kinase $-3 \beta$ \\
\hline H3К36me3 & H3K36 trimethylation \\
\hline H3K4me3 & H3K4 trimethylation \\
\hline Hcy & homocysteine \\
\hline HDL-C & high-density lipoprotein cholesterol \\
\hline HIF1 $\alpha$ & hypoxia-inducible factor $1 \alpha$ \\
\hline HMGCR & 3-hydroxy-3-methylglutaryl-coenzyme A reductase \\
\hline $\mathrm{HO}-1$ & heme oxygenase- 1 \\
\hline HQO-1 & NAD(P)H quinine oxidoreductase \\
\hline HSCs & hepatic stellate cells \\
\hline HUVEC & human umbilical vein endothelial cell \\
\hline Hyp & hydroxyproline \\
\hline IBil & indirect bilirubin \\
\hline ICAM-1 & intercellular adhesion molecule-1 \\
\hline IDE & insulin-degrading enzyme \\
\hline IFN- $\gamma$ & interferon gamma \\
\hline IL-10 & interleukin-10 \\
\hline IL-1 $\beta$ & interleukin 1 beta \\
\hline IL-6 & interleukin-6 \\
\hline $\operatorname{Imp}$ & importins \\
\hline iNOS & inducible nitric oxide synthase \\
\hline $\mathrm{I} \kappa \mathrm{B} \alpha$ & inhibitor of nuclear factor kappa B $\alpha$ \\
\hline JNK & c-Jun $\mathrm{N}$ terminal kinase \\
\hline KM & kunming Mice \\
\hline
\end{tabular}




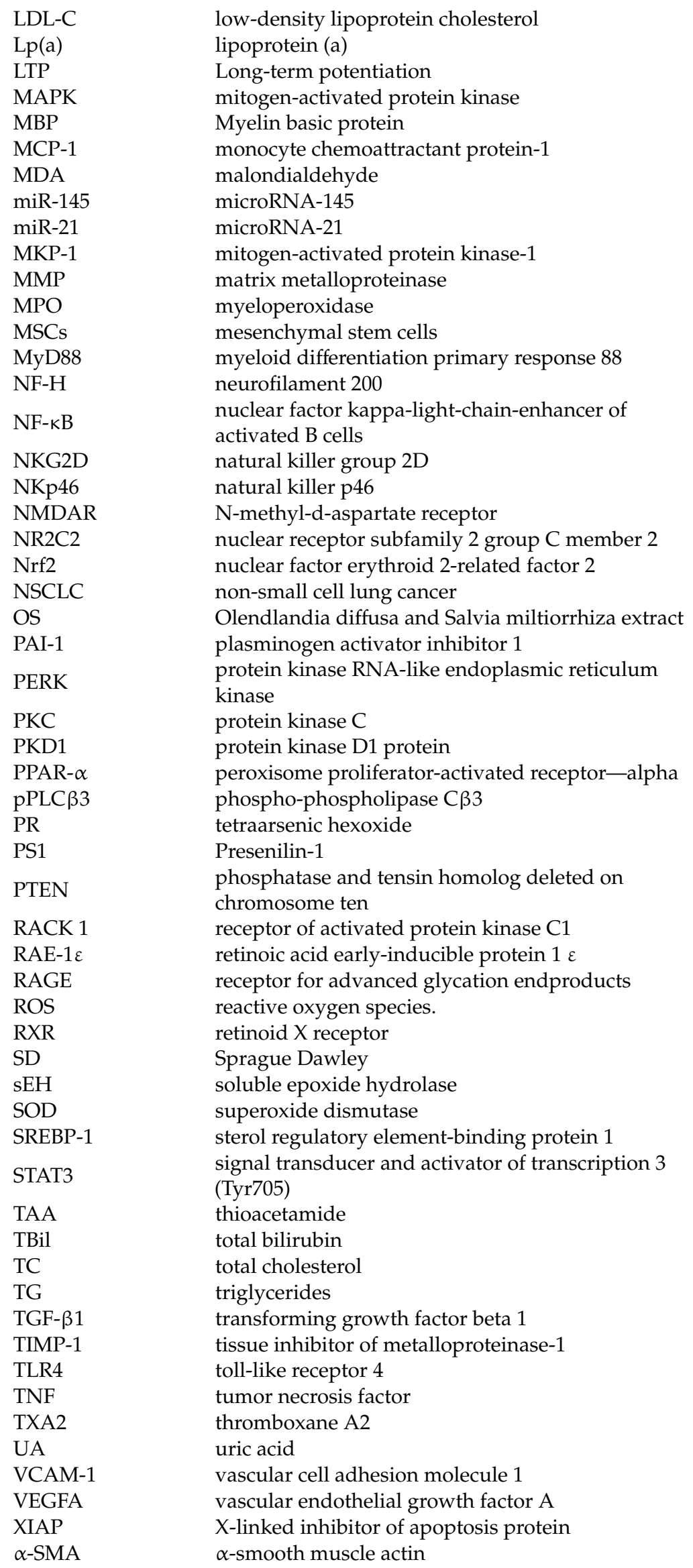




\section{References}

1. Zhou, L.; Zuo, Z.; Chow, M.S. Danshen: An overview of its chemistry, pharmacology, pharmacokinetics, and clinical use. J. Clin Pharmacol. 2005, 45, 1345-1359. [CrossRef] [PubMed]

2. Clebsch, B.; Barner, C.D. The New Book of Salvias: Sages for Every Garden; Timber Press: Portland, OR, USA, 2003.

3. Li, L.-N. Biologically active components from traditional Chinese medicines. In Pure and Applied Chemistry; IUPAC: Research Triangle Park, NC, USA, 1998; Volume 70, p. 547.

4. LI, M.H.; Peng, Y.; Xiao, P.G. Distribution of tanshinones in the genus Salvia (family Lamiaceae) from China and its systematic significance. J. Syst. Evol. 2010, 48, 118-122. [CrossRef]

5. Zhang, H.; Liu, Y.Y.; Jiang, Q.; Li, K.R.; Zhao, Y.X.; Cao, C.; Yao, J. Salvianolic acid A protects RPE cells against oxidative stress through activation of Nrf2/HO-1 signaling. Free Radic. Biol. Med. 2014, 69, $219-228$. [CrossRef] [PubMed]

6. Chen, Y.H.; Lin, S.J.; Ku, H.H.; Shiao, M.S.; Lin, F.Y.; Chen, J.W.; Chen, Y.L. Salvianolic acid B attenuates VCAM-1 and ICAM-1 expression in TNF-alpha-treated human aortic endothelial cells. J. Cell Biochem. 2001, 82, 512-521. [CrossRef]

7. Zhao, T.; Chang, L.; Zhang, B.; Lu, M.; Wang, X.; Orgah, J.O.; Wang, Y.; Tian, X.; Yang, J.; Fan, G.; et al. Specific Combination of Salvianolic Acids as Core Active Ingredients of Danhong Injection for Treatment of Arterial Thrombosis and Its Derived Dry Gangrene. Front. Pharmacol. 2017, 8, 361. [CrossRef]

8. Sun, B.; Li, C.; Zuo, L.; Liu, P. Protection of SAL B with H9C2 cells. Pharm. Biol. 2016, 54, 889-895. [CrossRef]

9. Yang, B.; Zheng, C.; Yu, H.; Zhang, R.; Zhao, C.; Cai, S. Cardio-protective effects of salvianolic acid B on oxygen and glucose deprivation (OGD)-treated H9c2 cells. Artif. Cells Nanomed. Biotechnol. 2019, 47, 2274-2281. [CrossRef]

10. Dong, Y.; Morris-Natschke, S.L.; Lee, K.H. Biosynthesis, total syntheses, and antitumor activity of tanshinones and their analogs as potential therapeutic agents. Nat. Prod. Rep. 2011, 28, 529-542. [CrossRef]

11. Hu, Q.; Wei, B.; Wei, L.; Hua, K.; Yu, X.; Li, H.; Ji, H. Sodium tanshinone IIA sulfonate ameliorates ischemia-induced myocardial inflammation and lipid accumulation in Beagle dogs through NLRP3 inflammasome. Int. J. Cardiol. 2015, 196, 183-192. [CrossRef]

12. Di Cesare Mannelli, L.; Piccolo, M.; Maione, F.; Ferraro, M.G.; Irace, C.; De Feo, V.; Ghelardini, C.; Mascolo, N. Tanshinones from Salvia miltiorrhiza Bunge revert chemotherapy-induced neuropathic pain and reduce glioblastoma cells malignancy. Biomed. Pharmacother. 2018, 105, 1042-1049. [CrossRef]

13. Yang, W.; Ju, J.H.; Jeon, M.J.; Han, X.; Shin, I. Danshen (Salvia miltiorrhiza) extract inhibits proliferation of breast cancer cells via modulation of Akt activity and p27 level. Phytother. Res. 2010, 24, 198-204. [CrossRef] [PubMed]

14. Sun, J.; Huang, S.H.; Tan, B.K.; Whiteman, M.; Zhu, Y.C.; Wu, Y.J.; Ng, Y.; Duan, W.; Zhu, Y.Z. Effects of purified herbal extract of Salvia miltiorrhiza on ischemic rat myocardium after acute myocardial infarction. Life Sci. 2005, 76, 2849-2860. [CrossRef] [PubMed]

15. Lee, T.Y.; Chang, H.H.; Wang, G.J.; Chiu, J.H.; Yang, Y.Y.; Lin, H.C. Water-soluble extract of Salvia miltiorrhiza ameliorates carbon tetrachloride-mediated hepatic apoptosis in rats. J. Pharm. Pharmacol. 2006, 58, 659-665. [CrossRef] [PubMed]

16. Zhou, Y.; Li, W.; Xu, L.; Chen, L. In Salvia miltiorrhiza, phenolic acids possess protective properties against amyloid $\beta$-induced cytotoxicity, and tanshinones act as acetylcholinesterase inhibitors. Environ. Toxicol. Pharmacol. 2011, 31, 443-452. [CrossRef] [PubMed]

17. Wang, L.; Ma, R.; Liu, C.; Liu, H.; Zhu, R.; Guo, S.; Tang, M.; Li, Y.; Niu, J.; Fu, M.; et al. Salvia miltiorrhiza: A Potential Red Light to the Development of Cardiovascular Diseases. Curr. Pharm. Des. 2017, 23, 1077-1097. [CrossRef] [PubMed]

18. Li, Z.M.; Xu, S.W.; Liu, P.Q. Salvia miltiorrhizaBurge (Danshen): A golden herbal medicine in cardiovascular therapeutics. Acta Pharmacol. Sin. 2018, 39, 802-824. [CrossRef]

19. Zhang, X.Z.; Qian, S.S.; Zhang, Y.J.; Wang, R.Q. Salvia miltiorrhiza: A source for anti-Alzheimer's disease drugs. Pharm. Biol. 2016, 54, 18-24. [CrossRef] [PubMed]

20. Ferlay, J.; Shin, H.R.; Bray, F.; Forman, D.; Mathers, C.; Parkin, D.M. Estimates of worldwide burden of cancer in 2008: GLOBOCAN 2008. Int. J. Cancer 2010, 127, 2893-2917. [CrossRef] 
21. Bray, F.; Ferlay, J.; Soerjomataram, I.; Siegel, R.L.; Torre, L.A.; Jemal, A. Global cancer statistics 2018: GLOBOCAN estimates of incidence and mortality worldwide for 36 cancers in 185 countries. CA Cancer J. Clin. 2018, 68, 394-424. [CrossRef]

22. Dasgupta, P.; Henshaw, C.; Youlden, D.R.; Clark, P.J.; Aitken, J.F.; Baade, P.D. Global Trends in Incidence Rates of Primary Adult Liver Cancers: A Systematic Review and Meta-Analysis. Front. Oncol. 2020, 10, 171. [CrossRef]

23. Kantarjian, H.M.; Prat, F.; Steensma, D.P.; Kurzrock, R.; Stewart, D.J.; Sekeres, M.A.; Leveque, J. Cancer research in the United States: A critical review of current status and proposal for alternative models. Cancer 2018, 124, 2881-2889. [CrossRef] [PubMed]

24. Lehky, T.J.; Leonard, G.D.; Wilson, R.H.; Grem, J.L.; Floeter, M.K. Oxaliplatin-induced neurotoxicity: Acute hyperexcitability and chronic neuropathy. Muscle Nerve 2004, 29, 387-392. [CrossRef] [PubMed]

25. Mileshkin, L.; Stark, R.; Day, B.; Seymour, J.F.; Zeldis, J.B.; Prince, H.M. Development of neuropathy in patients with myeloma treated with thalidomide: Patterns of occurrence and the role of electrophysiologic monitoring. J. Clin. Oncol. 2006, 24, 4507-4514. [CrossRef]

26. Baker, W.J.; Royer, G.L., Jr.; Weiss, R.B. Cytarabine and neurologic toxicity. J. Clin. Oncol. 1991, 9, 679-693. [CrossRef] [PubMed]

27. Kris, M.G.; Gralla, R.J.; Clark, R.A.; Tyson, L.B.; O'Connell, J.P.; Wertheim, M.S.; Kelsen, D.P. Incidence, course, and severity of delayed nausea and vomiting following the administration of high-dose cisplatin. J. Clin. Oncol. 1985, 3, 1379-1384. [CrossRef]

28. Jamali, J.; Dayo, A.; Adeel, A.; Qureshi, Y.; Khan, T.; Begum, S. A survey on gastrointestinal adverse drug reactions of Doxorubicin and Cyclophosphamide combination therapy. J. Pak. Med. Assoc. 2018, 68, 926-928. [PubMed]

29. Fan, C.; Cool, J.C.; Scherer, M.A.; Foster, B.K.; Shandala, T.; Tapp, H.; Xian, C.J. Damaging effects of chronic low-dose methotrexate usage on primary bone formation in young rats and potential protective effects of folinic acid supplementary treatment. Bone 2009, 44, 61-70. [CrossRef]

30. Kim, J.M.; Noh, E.M.; Song, H.K.; Lee, M.; Lee, S.H.; Park, S.H.; Ahn, C.K.; Lee, G.S.; Byun, E.B.; Jang, B.S.; et al. Salvia miltiorrhiza extract inhibits TPA-induced MMP-9 expression and invasion through the MAPK/AP-1 signaling pathway in human breast cancer MCF-7 cells. Oncol. Lett. 2017, 14, 3594-3600. [CrossRef]

31. Wu, C.; Chen, W.; Fang, M.; Boye, A.; Tao, X.; Xu, Y.; Hou, S.; Yang, Y. Compound Astragalus and Salvia miltiorrhiza extract inhibits hepatocellular carcinoma progression via miR-145/miR-21 mediated Smad3 phosphorylation. J. Ethnopharmacol. 2019, 231, 98-112. [CrossRef]

32. Boye, A.; Wu, C.; Jiang, Y.; Wang, J.; Wu, J.; Yang, X.; Yang, Y. Compound Astragalus and Salvia miltiorrhiza extracts modulate MAPK-regulated TGF-beta/Smad signaling in hepatocellular carcinoma by multi-target mechanism. J. Ethnopharmacol. 2015, 169, 219-228. [CrossRef]

33. Kim, C.; Song, H.S.; Park, H.; Kim, B. Activation of ER Stress-Dependent miR-216b Has a Critical Role in Salviamiltiorrhiza Ethanol-Extract-Induced Apoptosis in U266 and U937 Cells. Int. J. Mol. Sci. 2018, 19, 1240. [CrossRef]

34. Ye, Y.T.; Zhong, W.; Sun, P.; Wang, D.; Wang, C.; Hu, L.M.; Qian, J.Q. Apoptosis induced by the methanol extract of Salvia miltiorrhiza Bunge in non-small cell lung cancer through PTEN-mediated inhibition of PI3K/Akt pathway. J. Ethnopharmacol. 2017, 200, 107-116. [CrossRef] [PubMed]

35. Lee, H.; Lee, H.-J.; Bae, I.J.; Kim, J.J.; Kim, S.-H. Inhibition of STAT3/VEGF/CDK2 axis signaling is critically involved in the antiangiogenic and apoptotic effects of arsenic herbal mixture PROS in non-small lung cancer cells. Oncotarget 2017, 8, 101771. [CrossRef] [PubMed]

36. Wang, W.H.; Hsuan, K.Y.; Chu, L.Y.; Lee, C.Y.; Tyan, Y.C.; Chen, Z.S.; Tsai, W.C. Anticancer Effects of Salvia miltiorrhiza Alcohol Extract on Oral Squamous Carcinoma Cells. Evid. Based Complement. Alternat. Med. 2017, 2017, 5364010. [CrossRef] [PubMed]

37. Yang, C.Y.; Hsieh, C.C.; Lin, C.K.; Lin, C.S.; Peng, B.; Lin, G.J.; Sytwu, H.K.; Chang, W.L.; Chen, Y.W. Danshen extract circumvents drug resistance and represses cell growth in human oral cancer cells. BMC Complement. Altern. Med. 2017, 17, 555. [CrossRef] [PubMed]

38. Lee, J.; Choi, B.Y.; Keum, Y.S. Acetonitrile extract of Salvia miltiorrhiza Radix exhibits growth-inhibitory effects on prostate cancer cells through the induction of cell cycle arrest and apoptosis. Oncol. Lett. 2017, 13, 2921-2928. [CrossRef] 
39. Sung, B.; Chung, H.S.; Kim, M.; Kang, Y.J.; Kim, D.H.; Hwang, S.Y.; Kim, M.J.; Kim, C.M.; Chung, H.Y.; Kim, N.D. Cytotoxic effects of solvent-extracted active components of Salvia miltiorrhiza Bunge on human cancer cell lines. Exp. Ther. Med. 2015, 9, 1421-1428. [CrossRef]

40. Wu, C.F.; Bohnert, S.; Thines, E.; Efferth, T. Cytotoxicity of Salvia miltiorrhiza Against Multidrug-Resistant Cancer Cells. Am. J. Chin. Med. 2016, 44, 871-894. [CrossRef]

41. Dobhal, Y.; Parcha, V.; Dhasmana, D.C. Cardioprotective potential of Allium humile leaves extract. Orient. Pharm. Exp. Med. 2014, 14, 157-162. [CrossRef]

42. Virani, S.S.; Alonso, A.; Benjamin, E.J.; Bittencourt, M.S.; Callaway, C.W.; Carson, A.P.; Chamberlain, A.M.; Chang, A.R.; Cheng, S.; Delling, F.N.; et al. Heart Disease and Stroke Statistics-2020 Update: A Report from the American Heart Association. Circulation 2020, 141, e139-e596. [CrossRef]

43. Thomas, H.; Diamond, J.; Vieco, A.; Chaudhuri, S.; Shinnar, E.; Cromer, S.; Perel, P.; Mensah, G.A.; Narula, J.; Johnson, C.O.; et al. Global Atlas of Cardiovascular Disease 2000-2016: The Path to Prevention and Control. Glob. Heart 2018, 13, 143-163. [CrossRef]

44. Henderson, A. Coronary heart disease: Overview. Lancet 1996, 348 (Suppl. S1), S1-S4. [CrossRef]

45. Thygesen, K.; Alpert, J.S.; Jaffe, A.S.; Chaitman, B.R.; Bax, J.J.; Morrow, D.A.; White, H.D. Fourth Universal Definition of Myocardial Infarction (2018). J. Am. Coll. Cardiol 2018, 72, 2231-2264. [CrossRef] [PubMed]

46. Frangogiannis, N.G. Regulation of the inflammatory response in cardiac repair. Circ. Res. 2012, 110, 159-173. [CrossRef] [PubMed]

47. Prabhu, S.D.; Frangogiannis, N.G. The Biological Basis for Cardiac Repair After Myocardial Infarction: From Inflammation to Fibrosis. Circ. Res. 2016, 119, 91-112. [CrossRef]

48. Liu, B.; Du, Y.; Cong, L.; Jia, X.; Yang, G. Danshen (Salvia miltiorrhiza) Compounds Improve the Biochemical Indices of the Patients with Coronary Heart Disease. Evid. Based Complement. Alternat. Med. 2016, 2016, 9781715. [CrossRef]

49. Zhang, Y.; Wang, H.; Cui, L.; Zhang, Y.; Liu, Y.; Chu, X.; Liu, Z.; Zhang, J.; Chu, L. Continuing treatment with Salvia miltiorrhiza injection attenuates myocardial fibrosis in chronic iron-overloaded mice. PLOS ONE 2015, 10, e0124061. [CrossRef] [PubMed]

50. Ai, F.; Chen, M.; Li, W.; Yang, Y.; Xu, G.; Gui, F.; Liu, Z.; Bai, X.; Chen, Z. Danshen improves damaged cardiac angiogenesis and cardiac function induced by myocardial infarction by modulating HIF1 $\alpha /$ VEGFA signaling pathway. Int. J. Clin. Exp. Med. 2015, 8, 18311-18318.

51. Wang, L.; Yu, J.; Fordjour, P.A.; Xing, X.; Gao, H.; Li, Y.; Li, L.; Zhu, Y.; Gao, X.; Fan, G. Danshen injection prevents heart failure by attenuating post-infarct remodeling. J. Ethnopharmacol. 2017, 205, 22-32. [CrossRef]

52. Yang, J.; Wang, B.; Li, N.; Zhou, Q.; Zhou, W.; Zhan, Z. Salvia miltiorrhiza and Carthamus tinctorius Extract Prevents Cardiac Fibrosis and Dysfunction after Myocardial Infarction by Epigenetically Inhibiting Smad3 Expression. Evid. Based Complement. Alternat. Med. 2019, 2019, 6479136. [CrossRef]

53. Wang, Y.; Li, C.; Wang, Q.; Shi, T.; Wang, J.; Chen, H.; Wu, Y.; Han, J.; Guo, S.; Wang, Y.; et al. Danqi Pill regulates lipid metabolism disorder induced by myocardial ischemia through FATP-CPTI pathway. BMC Complement. Altern. Med. 2015, 15, 28. [CrossRef] [PubMed]

54. Mao, B.; Nuan, L.; Yang, L.; Zeng, X. Compatibility of Astragalus and Salvia extract inhibits myocardial fibrosis and ventricular remodeling by regulation of protein kinase D1 protein. Int. J. Clin. Exp. Med. 2015, 8, 3716-3724. [PubMed]

55. Ma, S.; Ma, J.; Mai, X.; Zhao, X.; Guo, L.; Zhang, M. Danqi soft capsule prevents infarct border zone remodelling and reduces susceptibility to ventricular arrhythmias in post-myocardial infarction rats. J. Cell Mol. Med. 2019, 23, 5454-5465. [CrossRef] [PubMed]

56. Xu, M.; Hao, H.; Jiang, L.; Long, F.; Wei, Y.; Ji, H.; Sun, B.; Peng, Y.; Wang, G.; Ju, W.; et al. In vitro inhibitory effects of ethanol extract of Danshen (Salvia miltiorrhiza) and its components on the catalytic activity of soluble epoxide hydrolase. Phytomedicine 2015, 22, 444-451. [CrossRef] [PubMed]

57. Huang, W.; Yang, Y.; Zeng, Z.; Su, M.; Gao, Q.; Zhu, B. Effect of Salvia miltiorrhiza and ligustrazine injection on myocardial ischemia/reperfusion and hypoxia/reoxygenation injury. Mol. Med. Rep. 2016, 14, 4537-4544. [CrossRef]

58. Kema, V.H.; Mojerla, N.R.; Khan, I.; Mandal, P. Effect of alcohol on adipose tissue: A review on ethanol mediated adipose tissue injury. Adipocyte 2015, 4, 225-231. [CrossRef] [PubMed]

59. de Alwis, N.M.; Day, C.P. Non-alcoholic fatty liver disease: The mist gradually clears. J. Hepatol. 2008, 48 (Suppl. S1), S104-S112. [CrossRef] 
60. Harris, R.; Harman, D.J.; Card, T.R.; Aithal, G.P.; Guha, I.N. Prevalence of clinically significant liver disease within the general population, as defined by non-invasive markers of liver fibrosis: A systematic review. Lancet Gastroenterol. Hepatol. 2017, 2, 288-297. [CrossRef]

61. Moon, A.M.; Singal, A.G.; Tapper, E.B. Contemporary Epidemiology of Chronic Liver Disease and Cirrhosis. Clin. Gastroenterol. Hepatol. 2019. [CrossRef]

62. Parker, R.; Aithal, G.P.; Becker, U.; Gleeson, D.; Masson, S.; Wyatt, J.I.; Rowe, I.A. Natural history of histologically proven alcohol-related liver disease: A systematic review. J. Hepatol. 2019, 71, 586-593. [CrossRef]

63. EASD. EASL-EASD-EASO Clinical Practice Guidelines for the Management of Non-Alcoholic Fatty Liver Disease. Obes. Facts 2016, 9, 65-90. [CrossRef]

64. Singh, S.; Osna, N.A.; Kharbanda, K.K. Treatment options for alcoholic and non-alcoholic fatty liver disease: A review. World J. Gastroenterol. 2017, 23, 6549-6570. [CrossRef] [PubMed]

65. Ding, L.; Wo, L.; Du, Z.; Tang, L.; Song, Z.; Dou, X. Danshen protects against early-stage alcoholic liver disease in mice via inducing PPARalpha activation and subsequent 4-HNE degradation. PLoS ONE 2017, 12, e0186357. [CrossRef] [PubMed]

66. Li, X.; Liu, Y.; Yue, W.; Tan, Y.; Wang, H.; Zhang, L.; Chen, J. A Compound of Chinese Herbs Protects against Alcoholic Liver Fibrosis in Rats via the TGF-beta1/Smad Signaling Pathway. Evid. Based Complement. Alternat. Med. 2019, 2019, 9121347. [CrossRef]

67. Butler, A.E.; Ramachandran, V.; Sathypalan, T.; David, R.; Gooderham, N.J.; Benurwar, M.; Dargham, S.R.; Hayat, S.; Hani Najafi-Shoushtari, S.; Atkin, S.L. microRNA Expression in Women With and Without Polycystic Ovarian Syndrome Matched for Body Mass Index. Front. Endocrinol. 2020, 11, 206. [CrossRef] [PubMed]

68. Zhou, X.; Cheung, C.M.; Yang, J.M.; Or, P.M.; Lee, W.Y.; Yeung, J.H. Danshen (Salvia miltiorrhiza) water extract inhibits paracetamol-induced toxicity in primary rat hepatocytes via reducing CYP2E1 activity and oxidative stress. J. Pharm. Pharmacol. 2015, 67, 980-989. [CrossRef]

69. Yang, L.; Huo, J.R.; Zhu, H.Y.; Chen, Z.; Wang, X.Y. The effect of Salvia miltiorrhiza in a mouse model of hepatic sinusoidal obstruction syndrome induced by Gynura segetum. Rev. Esp. Enferm. Dig. 2019, 111, 823-827. [CrossRef]

70. Gao, L.N.; Yan, K.; Cui, Y.L.; Fan, G.W.; Wang, Y.F. Protective effect of Salvia miltiorrhiza and Carthamus tinctorius extract against lipopolysaccharide-induced liver injury. World J. Gastroenterol. 2015, 21, 9079-9092. [CrossRef]

71. Parajuli, D.R.; Zhao, Y.Z.; Jin, H.; Chi, J.H.; Li, S.Y.; Kim, Y.C.; Sohn, D.H.; Lee, S.H. Anti-fibrotic effect of PF2401-SF, a standardized fraction of Salvia miltiorrhiza, in thioacetamide-induced experimental rats liver fibrosis. Arch. Pharm Res. 2015, 38, 549-555. [CrossRef]

72. Peng, Y.; Yang, T.; Huang, K.; Shen, L.; Tao, Y.; Liu, C. Salvia Miltiorrhiza Ameliorates Liver Fibrosis by Activating Hepatic Natural Killer Cells in Vivo and in Vitro. Front. Pharmacol. 2018, 9, 762. [CrossRef]

73. Lee, H.S.; Son, W.C.; Ryu, J.E.; Koo, B.A.; Kim, Y.S. Standardized Salvia miltiorrhiza extract suppresses hepatic stellate cell activation and attenuates steatohepatitis induced by a methionine-choline deficient diet in mice. Molecules 2014, 19, 8189-8211. [CrossRef]

74. Lee, M.M.; Kim, H.G.; Lee, S.B.; Lee, J.S.; Kim, W.Y.; Choi, S.H.; Lee, S.K.; Byun, C.K.; Hyun, P.M.; Son, C.G. CGplus, a standardized herbal composition ameliorates non-alcoholic steatohepatitis in a tunicamycin-induced mouse model. Phytomedicine 2018, 41, 24-32. [CrossRef] [PubMed]

75. Feng, Y.; Chen, Y.; Yang, B.; Lan, Q.; Wang, T.; Cui, G.; Ren, Z.; Choi, I.C.; Leung, G.P.; Yan, F.; et al. Hepatoprotective Effect of Jianpi Huoxue Formula on Nonalcoholic Fatty Liver Disease Induced by Methionine-Choline-Deficient Diet in Rat. Biomed. Res. Int. 2019, 2019, 7465272. [CrossRef] [PubMed]

76. Schneider, J.A.; Bennett, D.A. Where vascular meets neurodegenerative disease. Stroke 2010, 41, S144-S146. [CrossRef] [PubMed]

77. Lendahl, U.; Nilsson, P.; Betsholtz, C. Emerging links between cerebrovascular and neurodegenerative diseases-A special role for pericytes. EMBO Rep. 2019, 20, e48070. [CrossRef]

78. Iadecola, C. The overlap between neurodegenerative and vascular factors in the pathogenesis of dementia. Acta Neuropathol. 2010, 120, 287-296. [CrossRef]

79. Assal, F.; Sztajzel, R.; Carota, A.; Annoni, J.M.; Bogousslavsky, J. Neurodegeneration and cerebrovascular disease: Causal or incidental link? Rev. Med. Suisse 2006, 2, 1180-1182. 
80. Ferri, C.P.; Prince, M.; Brayne, C.; Brodaty, H.; Fratiglioni, L.; Ganguli, M.; Hall, K.; Hasegawa, K.; Hendrie, H.; Huang, Y.; et al. Global prevalence of dementia: A Delphi consensus study. Lancet 2005, 366, 2112-2117. [CrossRef]

81. Jack, C.R., Jr.; Knopman, D.S.; Jagust, W.J.; Petersen, R.C.; Weiner, M.W.; Aisen, P.S.; Shaw, L.M.; Vemuri, P.; Wiste, H.J.; Weigand, S.D.; et al. Tracking pathophysiological processes in Alzheimer's disease: An updated hypothetical model of dynamic biomarkers. Lancet Neurol. 2013, 12, 207-216. [CrossRef]

82. Sweeney, M.D.; Kisler, K.; Montagne, A.; Toga, A.W.; Zlokovic, B.V. The role of brain vasculature in neurodegenerative disorders. Nat. Neurosci. 2018, 21, 1318-1331. [CrossRef]

83. 2020 Alzheimer's disease facts and figures. Alzheimer's Dement. 2020, 16, 391-460. [CrossRef]

84. Parsons, C.G.; Stoffler, A.; Danysz, W. Memantine: A NMDA receptor antagonist that improves memory by restoration of homeostasis in the glutamatergic system-too little activation is bad, too much is even worse. Neuropharmacology 2007, 53, 699-723. [CrossRef] [PubMed]

85. Haake, A.; Nguyen, K.; Friedman, L.; Chakkamparambil, B.; Grossberg, G.T. An update on the utility and safety of cholinesterase inhibitors for the treatment of Alzheimer's disease. Expert Opin. Drug. Saf. 2020, 19, 147-157. [CrossRef] [PubMed]

86. Stoll, G.; Kleinschnitz, C.; Nieswandt, B. Molecular mechanisms of thrombus formation in ischemic stroke: Novel insights and targets for treatment. Blood 2008, 112, 3555-3562. [CrossRef] [PubMed]

87. Vijayan, M.; Reddy, P.H. Stroke, Vascular Dementia, and Alzheimer's Disease: Molecular Links. J. Alzheimers Dis. 2016, 54, 427-443. [CrossRef]

88. Sun, J.-H.; Tan, L.; Yu, J.-T. Post-stroke cognitive impairment: Epidemiology, mechanisms and management. Ann. Transl. Med. 2014, 2, 8.

89. Kawabori, M.; Yenari, M.A. Inflammatory responses in brain ischemia. Curr. Med. Chem. 2015, 22, $1258-1277$. [CrossRef]

90. Radak, D.; Katsiki, N.; Resanovic, I.; Jovanovic, A.; Sudar-Milovanovic, E.; Zafirovic, S.; Mousad, S.A.; Isenovic, E.R. Apoptosis and Acute Brain Ischemia in Ischemic Stroke. Curr. Vasc Pharmacol. 2017, 15, 115-122. [CrossRef]

91. Bright, R.; Mochly-Rosen, D. The Role of Protein Kinase C in Cerebral Ischemic and Reperfusion Injury. Stroke 2005, 36, 2781-2790. [CrossRef]

92. Yu, H.; Yao, L.; Zhou, H.; Qu, S.; Zeng, X.; Zhou, D.; Zhou, Y.; Li, X.; Liu, Z. Neuroprotection against Abeta25-35-induced apoptosis by Salvia miltiorrhiza extract in SH-SY5Y cells. Neurochem. Int. 2014, 75, 89-95. [CrossRef]

93. Paudel, P.; Seong, S.H.; Zhou, Y.; Park, C.H.; Yokozawa, T.; Jung, H.A.; Choi, J.S. Rosmarinic Acid Derivatives' Inhibition of Glycogen Synthase Kinase-3beta Is the Pharmacological Basis of Kangen-Karyu in Alzheimer's Disease. Molecules 2018, 23, 2919. [CrossRef]

94. Ozarowski, M.; Mikolajczak, P.L.; Piasecka, A.; Kujawski, R.; Bartkowiak-Wieczorek, J.; Bogacz, A.; Szulc, M.; Kaminska, E.; Kujawska, M.; Gryszczynska, A.; et al. Effect of Salvia miltiorrhiza root extract on brain acetylcholinesterase and butyrylcholinesterase activities, their mRNA levels and memory evaluation in rats. Physiol. Behav. 2017, 173, 223-230. [CrossRef] [PubMed]

95. Teng, Y.; Zhang, M.Q.; Wang, W.; Liu, L.T.; Zhou, L.M.; Miao, S.K.; Wan, L.H. Compound danshen tablet ameliorated abeta25-35-induced spatial memory impairment in mice via rescuing imbalance between cytokines and neurotrophins. BMC Complement. Altern. Med. 2014, 14, 23. [CrossRef] [PubMed]

96. Liu, M.; Guo, H.; Li, C.; Wang, D.; Wu, J.; Wang, C.; Xu, J.; Qin, R.A. Cognitive improvement of compound danshen in an Abeta25-35 peptide-induced rat model of Alzheimer's disease. BMC Complement. Altern. Med. 2015, 15, 382. [CrossRef] [PubMed]

97. Kim, R.; Lee, S.; Lee, C.Y.; Yun, H.; Lee, H.; Lee, M.Y.; Kim, J.; Jeong, J.Y.; Baek, K.; Chang, W. Salvia miltiorrhiza enhances the survival of mesenchymal stem cells under ischemic conditions. J. Pharm. Pharmacol. 2018, 70, 1228-1241. [CrossRef]

98. Wang, F.; He, Q.; Wang, J.; Yuan, Q.; Guo, H.; Chai, L.; Wang, S.; Hu, L.; Zhang, Y. Neuroprotective effect of salvianolate lyophilized injection against cerebral ischemia in type 1 diabetic rats. BMC Complement. Altern. Med. 2017, 17, 258. [CrossRef]

99. Fei, Y.X.; Wang, S.Q.; Yang, L.J.; Qiu, Y.Y.; Li, Y.Z.; Liu, W.Y.; Xi, T.; Fang, W.R.; Li, Y.M. Salvia miltiorrhiza Bunge (Danshen) extract attenuates permanent cerebral ischemia through inhibiting platelet activation in rats. J. Ethnopharmacol. 2017, 207, 57-66. [CrossRef] 
100. Zhang, X.; Zheng, W.; Wang, T.; Ren, P.; Wang, F.; Ma, X.; Wang, J.; Huang, X. Danshen-Chuanxiong-Honghua Ameliorates Cerebral Impairment and Improves Spatial Cognitive Deficits after Transient Focal Ischemia and Identification of Active Compounds. Front. Pharmacol. 2017, 8, 452. [CrossRef]

101. Cai, H.; Lian, L.; Wang, Y.; Yu, Y.; Liu, W. Protective effects of Salvia miltiorrhiza injection against learning and memory impairments in streptozotocin-induced diabetic rats. Exp. Ther. Med. 2014, 8, 1127-1130. [CrossRef]

102. Kim, M.S.; Bang, J.H.; Lee, J.; Kim, H.W.; Sung, S.H.; Han, J.S.; Jeon, W.K. Salvia miltiorrhiza extract protects white matter and the hippocampus from damage induced by chronic cerebral hypoperfusion in rats. BMC Complement. Altern. Med. 2015, 15, 415. [CrossRef]

103. Park, H.J.; Lee, S.; Jung, J.W.; Lee, Y.C.; Choi, S.M.; Kim, D.H. Salvia miltiorrhiza Bunge Blocks Ethanol-Induced Synaptic Dysfunction through Regulation of NMDA Receptor-Dependent Synaptic Transmission. Biomol. Ther. (Seoul) 2016, 24, 433-437. [CrossRef]

104. Zhang, Q.; Liu, X.; Yan, L.; Zhao, R.; An, J.; Liu, C.; Yang, H. Danshen extract (Salvia miltiorrhiza Bunge) attenuate spinal cord injury in a rat model: A metabolomic approach for the mechanism study. Phytomedicine 2019, 62, 152966. [CrossRef] [PubMed]

105. Jia, C.; Han, S.; Wei, L.; Dang, X.; Niu, Q.; Chen, M.; Cao, B.; Liu, Y.; Jiao, H. Protective effect of compound Danshen (Salvia miltiorrhiza) dripping pills alone and in combination with carbamazepine on kainic acid-induced temporal lobe epilepsy and cognitive impairment in rats. Pharm. Biol. 2018, 56, 217-224. [CrossRef] [PubMed]

106. Jun, H. Donguibogam. Seoul Donguibogam 1980, 2005, 1091.

107. Su, C.-Y.; Ming, Q.-L.; Rahman, K.; Han, T.; Qin, L.-P. Salvia miltiorrhiza: Traditional medicinal uses, chemistry, and pharmacology. Chin. J. Nat. Med. 2015, 13, 163-182. [CrossRef]

108. Hu, W.; Kavanagh, J.J. Anticancer therapy targeting the apoptotic pathway. Lancet Oncol. 2003, 4, $721-729$. [CrossRef]

109. Braicu, C.; Buse, M.; Busuioc, C.; Drula, R.; Gulei, D.; Raduly, L.; Rusu, A.; Irimie, A.; Atanasov, A.G.; Slaby, O.; et al. A Comprehensive Review on MAPK: A Promising Therapeutic Target in Cancer. Cancers 2019, 11, 1618. [CrossRef]

110. Parrish, A.B.; Freel, C.D.; Kornbluth, S. Cellular mechanisms controlling caspase activation and function. Cold Spring Harb. Perspect. Biol. 2013, 5. [CrossRef]

111. Steenbergen, C.; Frangogiannis, N.G. Chapter 36-Ischemic Heart Disease. In Muscle; Hill, J.A., Olson, E.N., Eds.; Academic Press: Cambridge, MA, USA, 2012; pp. 495-521. [CrossRef]

112. Hodzic, E. Potential Anti-Inflammatory Treatment of Ischemic Heart Disease. Med. Arch. 2018, 72, 94-98. [CrossRef]

113. Qamar, A.; Rader, D.J. Effect of interleukin $1 \beta$ inhibition in cardiovascular disease. Curr. Opin. Lipidol. 2012, 23, 548-553. [CrossRef]

114. McCarty, S.; Frishman, W. Interleukin 1 $\beta$ : A proinflammatory target for preventing atherosclerotic heart disease. Cardiol. Rev. 2014, 22, 176-181. [CrossRef]

115. Tian, J.; An, X.; Niu, L. Myocardial fibrosis in congenital and pediatric heart disease. Exp. Ther. Med. 2017, 13, 1660-1664. [CrossRef] [PubMed]

116. Reilly, K.R. Cardiac fibrosis: New treatments in cardiovascular medicine. U.S. Pharm. 2015, 40, 32-35.

117. Kong, P.; Christia, P.; Frangogiannis, N.G. The pathogenesis of cardiac fibrosis. Cell Mol. Life Sci. 2014, 71, 549-574. [CrossRef] [PubMed]

118. Domitrović, R.; Potočnjak, I. A comprehensive overview of hepatoprotective natural compounds: Mechanism of action and clinical perspectives. Arch. Toxicol. 2016, 90, 39-79. [CrossRef] [PubMed]

119. Medina, J.; Moreno-Otero, R. Pathophysiological basis for antioxidant therapy in chronic liver disease. Drugs 2005, 65, 2445-2461. [CrossRef] [PubMed]

120. Li, S.; Tan, H.Y.; Wang, N.; Zhang, Z.J.; Lao, L.; Wong, C.W.; Feng, Y. The Role of Oxidative Stress and Antioxidants in Liver Diseases. Int. J. Mol. Sci. 2015, 16, 26087-26124. [CrossRef] [PubMed]

121. Luedde, T.; Schwabe, R.F. NF-кB in the liver-linking injury, fibrosis and hepatocellular carcinoma. Nat. Rev. Gastroenterol. Hepatol. 2011, 8, 108-118. [CrossRef] 
122. Lawrence, T. The nuclear factor NF-kappaB pathway in inflammation. Cold Spring Harb. Perspect. Biol. 2009, 1, a001651. [CrossRef]

123. Sharma, P.; Srivastava, P.; Seth, A.; Tripathi, P.N.; Banerjee, A.G.; Shrivastava, S.K. Comprehensive review of mechanisms of pathogenesis involved in Alzheimer's disease and potential therapeutic strategies. Prog. Neurobiol. 2019, 174, 53-89. [CrossRef] 